\title{
Current status of glucocorticoid usage in solid organ transplantation
}

Simin Dashti-Khavidaki, Department of Clinical Pharmacy, Faculty of Pharmacy, Tehran University of Medical Sciences, Tehran, Iran. ORCHID: 0000-0003-2004-7845

Reza Saidi, Department of Surgery, SUNY Upstate Medical University, Syracuse NY 13210. ORCHID: 0000-0002-7389-2981

Hong Lu, Department of Pharmacology, SUNY Upstate Medical University, Syracuse NY 13210. ORCHID: 0000-0003-4389-7252

Supportive foundation: There is no funding support.

\section{Corresponding author:}

Hong Lu, PhD, Assistant Professor, Department of Pharmacology, SUNY Upstate Medical University, Syracuse NY 13210; luh@upstate.edu; Tel. (315) 464-7978; Fax. (315) 464-8008.

\begin{abstract}
Glucocorticoids (GCs) have been the mainstay of immunosuppressive therapy in solid organ transplantation (SOT) for decades due to their potent effects on the innate immunity and tissue protective effects. But, some SOT centers are reluctant to administer GCs for long-time due to the various side effects. This review summarizes advantages and disadvantages of GCs in SOT. PubMed and Scopus databases were searched from 2011 to April 2021 using search syntaxes cover "transplantation" and "glucocorticoids".

GCs are used in transplant recipients, transplant donors, and organ perfusate solution to improve transplant outcomes. In SOT recipients GCs are administered as induction and maintenance immunosuppressive therapy. GCs are also the cornerstone to treat acute anti-body- and T-cell-mediated rejections. Addition of GCs to organ perfusate solution and pretreatment of transplant donors with GCs are recommended by some guidelines and protocols to reduce ischemia-reperfusion injury peri-transplant. GCs with low bioavailability and high potency for GC receptors such as budesonide, nanoparticlemediated targeted delivery of GCs to specific organs, and combination use of dexamethasone with inducers of immune-regulatory cells are new methods of GC usage in SOT patients to reduce side effects or induce immune-tolerance instead of immunosuppression. Various side effects on different non-targeted organs/tissues such as bone, cardiovascular, neuromuscular, skin, and gastrointestinal tract have been noted for GCs. There are also potential drug-drug interactions for GCs in SOT patients.
\end{abstract}

Key words: Corticosteroids; Glucocorticoids; Solid organ transplantation; Liver; Kidney; Heart; Lung 
Core tip: Due to their potent immunosuppressive and anti-inflammatory effects, glucocorticoids (GCs) are widely used in solid organ transplantation (SOT). We herein review the current status of GC usage in SOT including their different clinical uses in transplant recipients and donors, new strategies for targeted organ delivery of GCs, and enhancing their immune-tolerance versus immunosuppressive effects. Major concerns about GCs such as their adverse effects on various organs and their potential drug-drug interactions in SOT patients are also discussed.

\section{Introduction}

Glucocorticoids (GCs) have long been used as induction and maintenance immunosuppressive therapy as well as treatment of acute allograft rejection in solid organ transplant (SOT) patients. However, complications of GCs make them undesirable for long-term use. Therefore, steroid sparing regimens have been used in different types of SOT[1-3].

French insurance data in 2014 showed that only 54\% of patients who received kidney transplantation in 2012 were taking prednisolone ${ }^{[4]}$. A large cohort study on adult liver transplant patients who were transplanted between 2006 and 2014 showed that during six months after transplantation approximately $43 \%$ of the liver transplant recipients were treated with three immunosuppressive drugs including prednisolone, a calcineurin inhibitor (CNI), and mycophenolate/azathioprine, while $15.4 \%$ of the patients were on steroid sparing regimens; however, approximately $34 \%$ of the patients on triple therapy changed to steroid sparing regimen between months 7 to 12 after liver transplantation ${ }^{2]}$. It should be kept in mind that this data underestimates the number of patients who discontinued steroid because patients who received only tacrolimus has been categorized as antimetabolite sparing not steroid sparing group.

Regarding heart transplantation, a report from International Society of Heart and Lung Transplantation Registry on adult heart recipients who were transplanted between 2000 and 2008 indicated that long-term use of steroids (use for more than 5 years after transplantation) has declined over time from $60 \%$ in the year 2000 to $43 \%$ in the year 2008, and early GC withdrawal (discontinuation between 2 to 5 years after transplantation) has increased from $19 \%$ to $33 \%$ during these years ${ }^{[3]}$. Here, we review different advantages and disadvantages of GCs in SOT (Figure 1). 
Figure 1: Advantages and disadvantages of glucocorticoids in solid organ transplantation

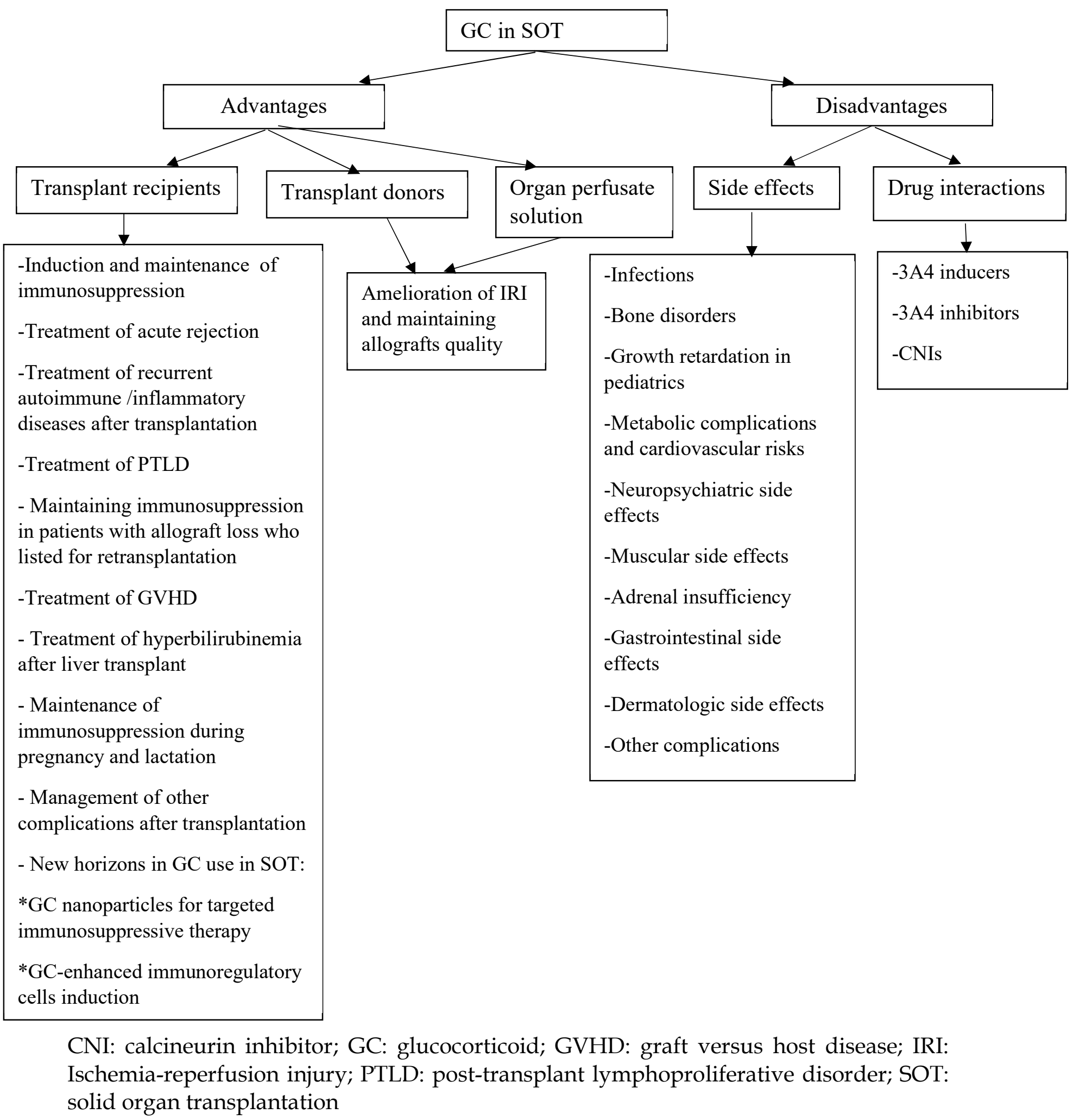




\section{Method}

PubMed and Scopus databases were searched from January 2011 to April 2021 using search syntaxes: (transplantation [Title/Abstract] OR transplant [Title/Abstract]) AND (corticosteroid* [Title/Abstract] OR glucocorticoid* [Title/Abstract] OR steroid* $^{*}$ [Title/Abstract] OR prednisolone [Title/Abstract] OR prednisone [Title/Abstract] OR methylprednisolone [Title/Abstract] OR dexamethasone [Title/Abstract] OR hydrocortisone [Title/Abstract]). Articles' references were reviewed for relevant publications.

\section{Mechanisms of actions of corticosteroids in solid organ transplantation}

For many years adaptive immunity system ( $T$ and $B$ cells) has been focused for preventing allograft rejection. However, innate immune system (dendritic cells, phagocytes (monocytes, macrophages, neutrophils), and natural killer (NK) cells) also play major roles in peritransplant immunologic process. Innate immunity is activated peritransplant by donor brain death, ischemia-reperfusion injury (IRI), non-adherence to immunosuppressive therapy, and infections. Innate immune activation ultimately induces acute allograft rejection and chronic allograft damage ${ }^{[5]}$. GCs exert a wide range of anti-inflammatory and immunosuppressive impacts mainly through their genomic and partly via their non-genomic effects. Their genomic effects that usually have prolonged onset of action, are mediated by binding of GCs to their cytosolic receptors, entering the nucleus and activating GC response elements that induce anti-inflammatory genes (transactivation) while repressing elements that induce expression of inflammatory factors such as nuclear factor kappa-light-chain enhancer of activated B-cells (NF-KB) and activator protein-1 (AP1) (transrepression). Anti-inflammatory effects of GCs are related to both transactivation and transrepression effects, while their adverse effects mainly correlated to their transactivation impacts. Genomic effects usually depend on cumulative dose over duration of GC administration [1, 5, 6]. Non-genomic mechanism of GCs has been less known and are partly mediated by membrane receptors that modulate anti-inflammatory and anti-oxidant effects. Their non-genomic effects are of rapid onset, short duration of action, and happens with high or pulse doses (prednisolone doses of more than $30 \mathrm{mg} /$ day) ${ }^{[1,6,7]}$.

Regarding the effects of GCs on innate immunity system, in dendritic cells GCs decrease the production of inflammatory cytokines (tumor necrosis factor (TNF)- $\alpha$ and interleukin (IL)-1 $\beta$ ) in response to CD40L and lipopolysaccharide (LPS). GCs also inhibit upregulation of costimulatory molecules (CD40, CD80, CD83, CD86 and MHC-II) in response to LPS. In monocytes, GCs increase the expression of anti-inflammatory cytokines (IL-10) and repress production of inflammatory cytokines (TNF- $\alpha$, IL-1 $\beta$, IL12), reduce expression of CD80 in response to inflammatory stimuli, impair monocyte antigen presenting activity, down-regulate expression of TLR4 on the surface of monocytes and subsequent monocyte hypo-responsiveness to endotoxin. In neutrophils, GCs inhibit neutrophil activation (by reducing the expression of NADPH oxidase, inducible nitric oxide synthase (iNOS), and cyclooxygenase 2), reduce chemotaxis, 
phagocytosis and cytokine secretions, increase the expression of some receptors for ILs and proinflammatory leukotrienes (IL1R1, BLT1), and reduce neutrophil sensitivity to apoptosis that leads to increased neutrophil life span. GCs reduce NK cell cytolytic activity and increase their production of pro-inflammatory cytokines ${ }^{[8]}$. By repressing the expression of IL-1, IL-2, IL-3, TNF- $\alpha$, and IFN- $\gamma$, T-cell activation process (a part of adaptive immunity) is inhibited by GCs ${ }^{[5]}$. These mechanisms have been summarized in Figure 2. Considering above-mentioned mechanisms, GCs have various advantages and disadvantages in SOT patients that are reviewed here.

Figure 2. Effects of GCs on immune system

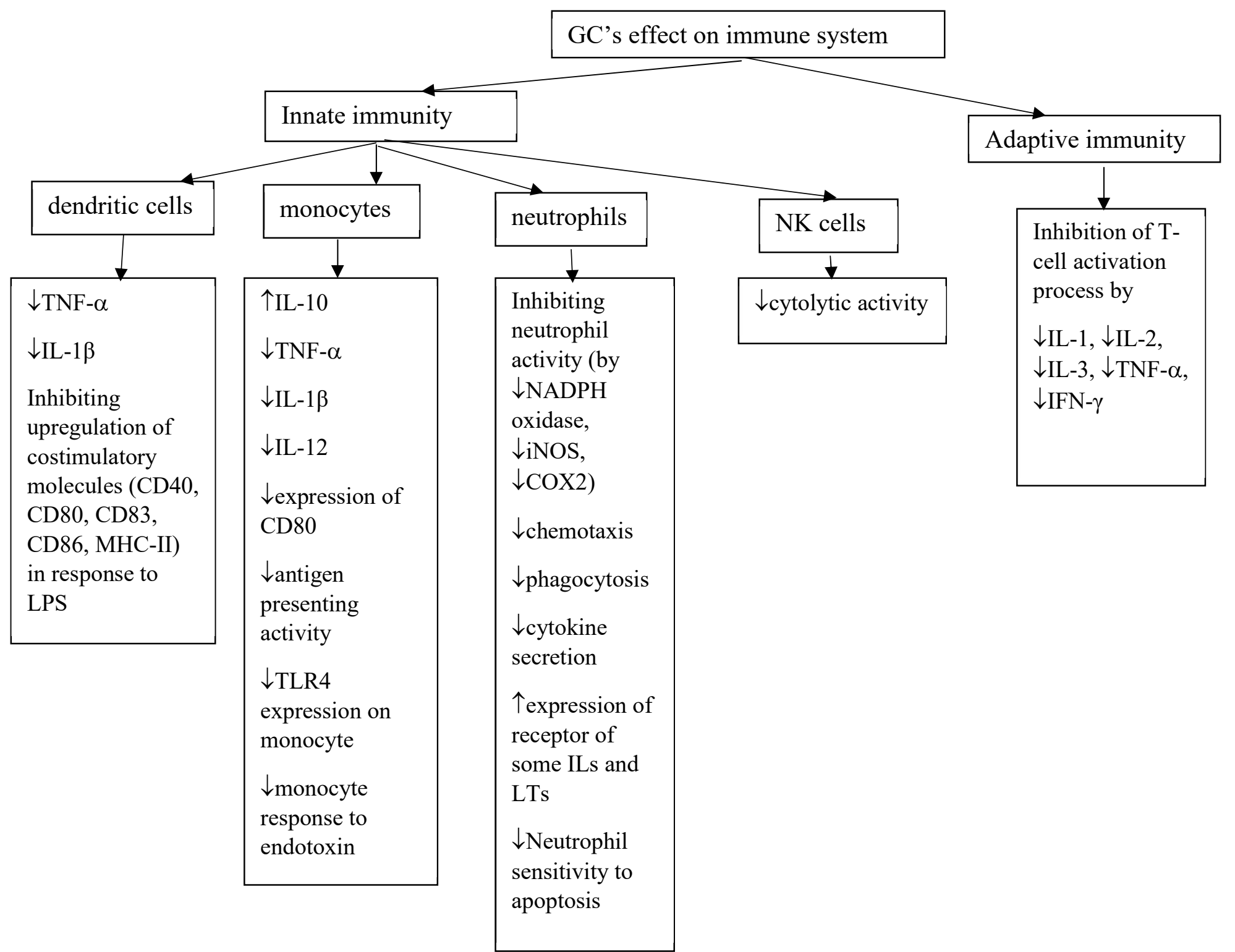

COX2: cyclooxygenase 2; IFN- $\gamma$ : interferon-gama; IL: interleukins; iNOS: inducible nitric oxide synthase; LT: leukotrienes; NK cells: natural killer cells; TNF- $\alpha$ : tumor necrosis factor-alpha 


\section{Advantages of GCs in SOT}

GCs are administered pre-transplant in potential donors and organ perfusate solution to decrease IRI and preserve organs quality, and GCs are given peri- and post-transplant to recipients as induction or maintenance immunosuppression, treatment of acute rejection, or for management of some post-transplant complications.

\section{Transplant recipients}

\subsection{GCs as induction and maintenance immunosuppressive therapy}

GCs are commonly used as induction and maintenance immunosuppressive agents in SOT patients[1-3]. As maintenance immunosuppressive therapy, some centers are shifting toward steroid sparing maintenance immunosuppressive regimens by different steroid withdrawal or avoidance protocols ${ }^{[1-3]}$. Steroid sparing means rapid, early, or late steroid discontinuation (within one week to several months after transplantation), while steroid avoidance refers to avoiding steroid use in regimens with or without initial high corticosteroid induction therapy ${ }^{[3,9-12]}$. Although old studies on steroid sparing regimens that usually were GC minimization or discontinuation after 3 months of transplant surgery showed higher rates of acute rejection and graft loss, in those studies immunosuppressive regimens contained cyclosporine as a CNI[13]. Nowadays, induction therapies with thymoglobulin or IL2 receptor antagonists and new maintenance immunosuppressive regimens such as tacrolimus instead of cyclosporine as CNI or mTOR inhibitors in combination with low doses of CNIs and/or mycophenolate provided the opportunity for successful steroids sparing immunosuppression regimens ${ }^{[1,}$ 9-11,14,15]. Although, firstly steroid sparing immunosuppressive regimens were used for low immunologic risk patients, an analysis of 169479 renal transplant patients using SRTR exhibited that rapid discontinuation of steroids can be used in all adult and pediatric first kidney transplant recipients from deceased or living donor and even in second kidney transplant recipients from living donor or patients at risk for rejection or recurrence of underlying diseases, without decreasing patients' or graft survivals. Only in adult patients with second kidney transplantation from deceased donor, rapid steroid withdrawal was associated with worse graft survival[9]. Another systematic review and meta-analysis consisting 7 cohort studies that included even high-risk kidney transplant patients such as re-transplant patients, African-American ethnicity or recipients with panel reactive antibody (PRA) of $20 \%$ or more found that acute rejection episodes and graft loss were comparable between patients maintained on steroids compared with steroid withdrawal or avoidance group. Steroid withdrawal was done within 1 week after transplantation in many of these patients. Based on this meta-analysis, steroid withdrawal within 1 week after transplantation was associated with significant reduced risk of patient death ${ }^{[10]}$.

Steroid withdrawal regimens are used in most liver transplant patients. A Cochrane systematic review consisting 1347 liver transplant patients revealed that early steroid 
withdrawal or steroid avoidance (excluding intraoperative GC use) have been beneficial in some patients especially those at risk for hypertension or diabetes mellitus[11]. Although steroid avoidance after using high intraoperative dose may be beneficial in liver transplant recipients, data showed that complete steroid avoidance (even avoiding intraoperative use) led toward decreased patient and graft survival ${ }^{[12]}$.

Most centers of simultaneous kidney and pancreas transplantations are also shifting toward steroid avoidance, or early or late steroid withdrawal[16].

Long term GC therapy had been conventionally the cornerstone of immunosuppressive therapy in heart transplant patients. However, a report from International Society of Heart and Lung Transplantation Registry on adult heart recipients who were transplanted between 2000 and 2008 showed that early or late GC withdrawal has increased among heart transplant patients. Comparing to long-term steroid users (GC use for more than 5 years after transplantation), 10-year patient survival was significantly higher among early (GC discontinuation between 2 to 5 years after transplantation) or late (GC discontinuation after year 5 of transplant) steroid withdrawal $(73 \%, 82 \%$ and $80 \%$, respectively $)^{[3]}$. Steroid discontinuation during 1 week after transplantation has also been applied in low-risk heart transplant pediatrics with acceptable 1-year outcomes ${ }^{[17]}$.

Corticosteroids are usually a part of maintenance immunosuppression in lung transplant patients as well. Glucocorticoid receptor (GR) in lung epithelia is essential for lung development, and GCs are widely used to treat certain lung diseases ${ }^{[18]}$. It seems that there is a difference in lung transplant outcomes between patients with different variants of glucocorticoid-induced transcript 1 gene (GLCCI1) that modulates GC sensitivity. A study on 71 lung transplant recipients showed that compared with those with the CC variant (wild type allele), patients with the TT variant (homozygous for mutant allele) had lower total lung capacity and forced expiratory volume in 1 second at 3 years after transplantation and also had significantly decreased chronic allograft dysfunction-free survival at year 3 after transplantation[19].

Despite available data regarding efficacy of steroid sparing regimens in SOT patients, systemic steroids are still used at least for several weeks in maintenance immunosuppression regimens even in low immunologic transplant types such as liver transplantation ${ }^{[2]}$. Budesonide is a synthetic corticosteroid with minimal systemic bioavailability of about $10 \%$ due to extensive first pass hepatic metabolism that result in its lower side effect[21]. On the other hand, compared to methylprednisolone and prednisone, budesonide possesses strong local anti-inflammatory effect in the liver due to approximately 15-times higher affinity to GR[22]. A phase 2 clinical study in first liver transplant recipients compared budesonide (tapering from 9 to $3 \mathrm{mg}$ over 12 weeks) with prednisolone in the maintenance immunosuppressive regimen containing CNI and mycophenolate. Patients were followed for two years. Biopsy proven acute cellular rejection was the same between the two groups (5\% in each group), while PTDM $(0 \%$ versus $15 \%)$ and infection rates $(0 \%$ versus $30 \%)$ were significantly lower in the budesonide taking group ${ }^{[23]}$. 


\subsection{Treatment of acute rejection}

High doses of intravenous (methylprednisolone or dexamethasone) or oral (prednisolone, prednisone) GCs have been historically administered for the treatment of acute cellular and antibody mediated rejections in different types of SOT[24-28].

Recently, a US center retrospectively assessed the 6-month outcomes of 29 pediatric liver transplant who were prescribed oral budesonide at outpatient setting for treatment of biopsy proven (19 patients) or presumed (based on blood biochemistry tests; 10 patients) mild to moderate acute cellular rejection. In these patients, budesonide was administered at daily doses of 6 to $9 \mathrm{mg}$ for several weeks and tapering down thereafter. Only 3 patients needed switching to systemic GCs (methylprednisolone or prednisone). All other patients experienced significant decreases in liver transaminases without progressive graft injury or chronic allograft rejection ${ }^{29]}$.

\subsection{Post-transplant malignancies}

A main complication after solid organ transplantation is post-transplant malignancies including post-transplant lymphoproliferative disorders (PTLD). Immunosuppression reduction or changes is recommended in patients with PTLD. However, GCs are a basis of chemoimmunotherapy in some malignancies including PTLD and are usually remained in immunosuppressive regimen of solid organ transplant recipients with PTLD ${ }^{[30]}$. Sometimes under the umbrella of corticosteroids, other chemotherapeutic agents with some concerns in SOT recipients are administered. Although immune checkpoint inhibitors are increasingly shown to be successful in treating multiple types of cancer, there are some concerns about the risk of allograft rejection with these drugs in SOT patients[31]. A pilot study showed that immune checkpoint inhibitors along with prophylactic steroids may be a safe and effective treatment for some solid organ transplant patients with advanced cutaneous squamous cell carcinoma[32]. While a Danish historical cohort study revealed a tendency toward higher occurrence of posttransplant cancer in a kidney transplant center that applied steroid-free immunosuppressive regimen compared to centers that adhered to GC-containing immunosuppressive protocols[33], another Danish registry analysis on over 59000 patients found a standardized incidence risk of 1.32 (95\% 1.09-1.59) for cutaneous squamous cell cancer among GC users, however, this increased risk was seen across all patients in that study not just transplant patients ${ }^{[34]}$.

\subsection{Prevention or treatment of recurrent autoimmune diseases}

Diverse de novo autoimmune diseases in different organs can happen after SOT and are usually treated as patients in the general population that is out of the scope of this review. Recurrent glomerulonephritis (GN) after renal transplantation is the fourth common cause of allograft loss with reported recurrence rate of $2.6 \%$ to $50 \%$ and average graft loss risk of $8.4 \%$ over 10 years. Data from Australia and New Zealand Dialysis and Transplant Registry over 30 years reported that focal segmental glomeruosclerosis (FSGS), IgA nephropathy, membranous GN, and membranoproliferative GN (MPGN) showed 
recurrence after renal transplantation. Different risk factors have been reported for these GN recurrence. Regarding the role of GCs, when all GNs were totally included, multivariate analysis exhibited that baseline steroid use in maintenance immunosuppression had a protective effect (adjusted HR: 0.54; 95\% CI 0.37-0.76, $\mathrm{P}<0.001)$. When FSGS and IgA nephropathy were analyzed separately, baseline steroid use was a protective factor only for transplant recipients with IgA nephropathy ${ }^{[3]}$. Another study also revealed that the rate of recurrence of IgA nephropathy after kidney transplantation was higher among patients with steroid withdrawal at any time after transplant ${ }^{[36]}$. There is paucity of enough evidence for treatment and outcomes of recurrent GN after transplantation. Recurrent GN after transplantation is usually managed similar to de novo ones in the general population, although sometimes with some different protocols and responses. GCs are usually a part of GN management

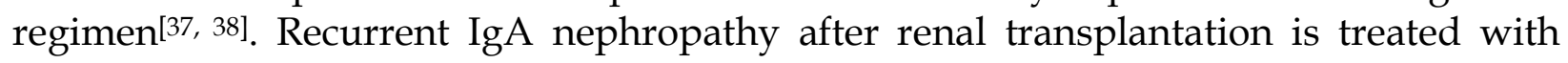
GCs[39].

Autoimmune liver diseases (autoimmune hepatitis (AIH), primary biliary cirrhosis (PBC), and primary sclerosing cholangitis (PSC)) may recur after liver transplantation with varying rates of $10 \%$ to $50 \%$. Recurrence of PBC or PSC has net been associated with dose or duration of CGs administration or discontinuing of GCs. Recurrent PBC is traditionally treated with ursodexycholic acid with varying results. Recurrent PSC usually causes progressive allograft damage and need for repeat liver transplantation. Although overall dose and duration of GC treatment pre- and post-liver transplantation were not related to AIH recurrence, rapid weaning of GC after liver transplantation has been associated with higher $\mathrm{AIH}$ recurrence rate. AIH recurrence is usually treated with GCs $[40,41]$.

\subsection{Maintaining immunosuppression in patients with graft loss who listed for re- transplantation}

Although maintenance of low dose CNI after kidney allograft loss can decrease the development of donor-specific antibody and repress the rise in PRA in patients listed for repeat kidney transplantation, such effects were not observed with GCs ${ }^{[42]}$. Meanwhile, some clinicians continue low dose prednisolone in kidney recipients with graft loss more than one year after transplantation who are planned for repeat renal transplantation within 1 year ${ }^{[33]}$.

\subsection{Graft versus host disease (GVHD) after SOT}

Although rare after SOT, GVHD may still occur. Case series show administration of methylprednisolone for treatment of GVHD in some SOT patients, however, there are GC-treatment refractory patients with high mortality rate of $82 \%[44,45]$.

\subsection{Hyperbilirubinemia after liver transplantation}

Hyperbilirubinemia after liver transplantation is common and is sometimes due to early allograft dysfunction. A randomized controlled trial assessed the effect of low dose 
steroid in combination with ursodeoxycholic acid in liver transplant patients. Control group received only ursodeoxycholic acid. Patients with hyperbilirubinemia due to biliary complications and acute rejection were excluded from the study. Both groups were comparable regarding immunosuppressive regimen, donor and recipient characteristics, and time after transplantation surgery. Steroid group had significantly lower bilirubin concentration 1 day and 15 days after intervention was completed and has shorter hospital stay compared with the control group ${ }^{[46]}$.

\subsection{Pregnancy and lactation}

GCs crosses the placenta, but near $90 \%$ of the dose of prednisolone and methylprednisolone (and to lesser extent dexamethasone and betamethasone) are metabolized by placenta $11 \beta$-hydroxysteroid dehydrogenase $2(11 \beta$-HSD2) to inactive metabolite. Although, there were concerns about oral-facial clefts, hypothalamuspituitary-adrenal (HPA) axis dysfunction, or retard growth in newborns from GC-taking mothers, the risk seems minimal unless there is 11 $\beta$-HSD2 dysfunction (for example due to preeclampsia in mother). It should be kept in mind that GCs may predispose pregnant women to hypertension and preeclampsia. Taken together, GCs in daily doses equivalent to less than $20 \mathrm{mg}$ prednisolone is considered acceptable in pregnant women, and GCs are usually continued in transplanted mothers. GCs are also considered compatible with breast-feeding ${ }^{[47]}$.

\subsection{Management of other complications}

The number of patients with pulmonary complications after hematopoietic stem cell transplantation (HSCT) is increasing, and some of these patients need lung transplantation to survive. Steroid therapy is the current treatment for pulmonary complications in HSCT patients. A retrospective study that compared 9 patients on lowdose and 13 patients on high-dose GCs for post-HSCT pulmonary complications and before their lung transplantation showed that taking low-dose versus high-dose GCs before lung transplantation in these patients was associated with significantly less complications during first year after lung transplantation and improved long-term survival[48].

\subsection{New horizons of GCs use in SOT recipients}

Targeted delivery of GCs to goal organ is a favorable method to reduce GC side effects when used for treatment of inflammatory diseases and in SOT patients. After parenteral administration, nanoparticles largely translocate into the liver by passive targeting. Therefore, nanoparticle-mediated drug delivery would be a promising method for treatment of inflammatory liver diseases. In several studies, different nanoparticles have been used for transportation of dexamethasone, such as biodegradable polymers (PLGA, PLLA, PCL, cellulose, cyclodextrin, chitosan, polyglutamic acid, and lipids), inorganic materials, polymer micelles, liposome, and carbon nanotubes. Entrapment of dexamethasone in these nanoparticles resulted in prolonged and sustained release of dexamethasone, but premature release out of the target organ was an undesired matter 
yet. To overcome this issue, dexamethasone in concentrations up to $100 \mathrm{mg} / \mathrm{ml}$ in olive oil were encapsulated in core-shell silica nanocapsules. During an experimental study, these nanocapsules were internalized by non-parenchymal murine liver cells and resulted in suppression of inflammatory response of liver macrophages and significant decrease in inflammatory cytokines. Pegylation of these nanocapsules led to good stability in plasma and controlled interaction with blood proteins ${ }^{[49]}$.

With the hope of improving efficacy while decreasing side effects, another animal study compared liposomal encapsulated prednisolone versus conventional prednisolone in a murine model of acute renal allograft rejection. The liposomes were 100-nm phospholipid bilayer vesicles coated with polyethyleneglycol. These liposomes remained in blood for several days after intravenous injection. Liposomes prevent the encapsulated drug to diffuse over blood vessel endothelial cells and spread over the body, while they are small enough to extravasate and accumulate in inflamed sites with increased vascular permeability, where macrophages and other phagocytic cells digest the vesicles and release the entrapped GC. The results of that animal study showed improved renal bioavailability of prednisolone, increased renal perfusion, and decreased cellular infiltrate in allograft by liposomal prednisolone compared with conventional prednisolone. In that study, liposomes were detected in other organs such as liver, stomach, and intestine but in much lower density than the kidney allograft [50]. More animal studies are needed before clinical studies to bring these bench findings to the bedside.

Inducing immune tolerance and eliminating the need for long term immunosuppressive therapy has been an old ideal in SOT. Modulating immunoregulatory cells are a potential target for this purpose. Myeloid derived suppressor cells (MDSCs) are novel immunoregulatory cells and are induced by granulocyte macrophage colony stimulating factor (GM-CSF). In an in vitro study, combination of dexamethasone with GM-CSF was successful for enhanced production of phenotype of MDSCs with enhanced in vitro immunosuppressive activity. Adoptive transfer of these MDSCs significantly enhanced expansion of regulatory $\mathrm{T}$ cells and prolonged heart allograft survival in mice model. Mechanistic studies showed that iNOS signaling was required for MDSCs in the control of T-cell response. GR signaling had major role in the recruitment of transferred MDSCs into allograft through upregulating CXCR2 expression on MDSCs. These findings revealed that co-administration of dexamethasone and GM-CSF may be a new and applicable strategy for the induction of immune tolerance in SOT[51].

\section{Transplant donors}

Brain death process induces inflammatory response in the donor. Increased intracranial pressure and decreased cerebral blood flow during brain death process activate neurohormonal systems and inflammatory cascade. Increased release of inflammatory cytokines, chemokines, and adhesion molecules leads to infiltration of T-lymphocytes and macrophages into the organs ${ }^{[52]}$. This inflammatory response causes allografts injury 
that in combination with IRI increases the risk of initial allograft poor function [53]. There are two separate stages for IRI. Ischemia leads to cellular metabolic disturbances, glycogen consumption, lack of oxygen supply, and ATP depletion which lead to initial parenchymal cell death. Reperfusion injury results from both metabolic disruptions and intense inflammatory response. IRI triggers inflammatory response mainly through innate immune response. Innate immune activation leads to increased production of cytokines, chemokines, and reactive oxygen species (ROS), and increased expression of adhesion molecules. Moreover, cross-talk between innate and adaptive immunity trigger adaptive immune response that results in tissue infiltration by lymphocytes and monocytes and graft rejection ${ }^{[54]}$. IRI is an important cause of early allograft dysfunction [54]. Therefore, several investigators administered anti-inflammatory drugs to deceased donors to ameliorate IRI. Although animal[55, 56] and small clinical studies ${ }^{[57]}$ showed that administering GCs to brain death donors decreased IRI in kidney, heart, or liver grafts [55-57] and is recommended by organ procurement guidelines [58], the effect of pretreatment of brain death donors with anti-inflammatory agents on long-term allografts outcomes are not promising $[59,60]$. A multicenter randomized controlled trial consisting 455 kidney transplant recipients from 306 deceased donors were followed for 5 years after transplantation. These deceased donors were randomized to receive $1 \mathrm{~g}$ of methylprednisolone or placebo before organ procurement. The incidence of biopsyconfirmed rejection (Banff $>1$ ) at 3 months after transplantation and 5-year graft survival and the mean estimated glomerular filtration rates were comparable between steroid and placebo groups ${ }^{[59]}$. In addition, a meta-analysis on methylprednisolone treatment of brain death liver donors (two studies, 183 participants) showed no effect of the treatment on rates of acute rejection (Table 1)[61]. Interestingly, an animal study showed that pretreatment with methylprednisolone markedly prevented warm liver IRI in normal rats, but aggravated IRI in the steatotic livers of the diabetic Zucker rats with deficiency of the leptin receptor [62]. Leptin resistance is common in diabetes. Thus, more studies are needed to understand how deficiency in the leptin signaling may switch the GC action from protection to aggravation in liver IRI and thus affect GC action in SOT of liver and other organs in humans. 
Table 1. The effect of pretreatment of transplant donors with methylprednisolone on SOT outcomes

\begin{tabular}{|c|c|c|c|}
\hline $\begin{array}{l}\text { Type of the } \\
\text { study }\end{array}$ & $\begin{array}{l}\text { Type of } \\
\text { SOT }\end{array}$ & $\begin{array}{l}\text { Follow-up } \\
\text { duration }\end{array}$ & Findings \\
\hline $\mathrm{RCT}^{[57]}$ & Liver & 6 months & $\begin{array}{l}\text { Significant lower liver enzymes in GC } \\
\text { versus placebo group at } 1^{\text {st }} \text { and } 10^{\text {th }} \\
\text { day after transplantation; } \\
\text { No difference in PNF rate between } \\
\text { groups ( } 2 \text { of } 50 \text { patients in GC and } 3 \text { of } \\
50 \text { patients in the placebo group); } \\
\text { Lower acute rejection during } 6 \text { months } \\
\text { in GC group ( } 22 \% \text { vs. } 36 \%, P<0.05)\end{array}$ \\
\hline $\mathrm{RCT}^{[60]}$ & Liver & $\begin{array}{l}\text { Maximum } 3 \\
\text { years }\end{array}$ & $\begin{array}{l}\text { No difference in liver enzymes } \\
\text { between GC and placebo groups } \\
\text { during } 1^{\text {st }} \text { week after transplantation; } \\
\text { Acute rejection during } 3 \text { months after } \\
\text { transplantation was } 24 \% \text { in each } \\
\text { group; } \\
1 \text {-year graft loss } 15 \% \text { in GC and } 24 \% \text { in } \\
\text { the placebo group (P=0.41); } \\
\text { Relative risk of acute rejection in GC } \\
\text { versus placebo group: } 1.02 \text { ( } 95 \text { CI: } 0.5- \\
2.1 ; P=1 \text { ); } \\
\text { Relative risk of mortality in GC versus } \\
\text { placebo group: } 0.63 \text { ( } 95 \% \text { CI: } 0.29-1.36 ; \\
P=0.31 \text { ) }\end{array}$ \\
\hline $\begin{array}{l}\text { Meta- } \\
\text { analysis of } \\
\text { two above } \\
\text { RCTs }\end{array}$ & Liver & $\begin{array}{l}\text { Maximum } 6 \\
\text { months }\end{array}$ & $\begin{array}{l}\text { Risk ratio for incidence of acute } \\
\text { rejection during } 1 \text { to } 6 \text { months after } \\
\text { transplantation: } 0.72 \text { (95\% CI: } 0.44-1.19 \text {, } \\
P=0.2 \text { ) }\end{array}$ \\
\hline RCT[59] & kidney & 5 years & $\begin{array}{l}\text { 3-month BPAR: } 10 \% \text { in GC and } 12 \% \text { in } \\
\text { placebo group }(\mathrm{P}=0.468) ; \\
5 \text {-year graft survival:84\% in GC and } \\
82 \% \text { in placebo group }(\mathrm{P}=0.941) ; \\
\text { Mean eGFR at } 5 \text { years: } \\
47 \mathrm{ml} / \mathrm{min} / 1.73 \mathrm{~m}^{2} \text { in } \mathrm{GC} \text { and } \\
48 \mathrm{ml} / \mathrm{min} / 1.73 \mathrm{~m}^{2} \text { in placebo group } \\
(\mathrm{P}=0.756)\end{array}$ \\
\hline
\end{tabular}

BPAR: biopsy-proven acute rejection; GC: glucocorticoid; PNF: primary non-function; RCT: randomized clinical trial; SOT: solid organ transplantation 
The pro-inflammatory state induced by brain death process also decreases the quality of lungs for donation. To preserve lung quality, methylprednisolone is administered to donors with various doses. To assess the dose-effect association between methylprednisolone and brain-death lung inflammation, an animal study compared low $(5 \mathrm{mg} / \mathrm{kg})$, intermediate $(12.5 \mathrm{mg} / \mathrm{kg})$, and high doses $(22.5 \mathrm{mg} / \mathrm{kg})$ of methylprednisolone. All methylprednisolone doses decreased inflammatory cytokines such as TNF- $\alpha$, IL-6, and IL- $1 \beta$. Intermediate and high doses of methylprednisolone also increased protective anti-inflammatory response as established by increased IL-10 expression. Macrophage chemotaxis was attenuated with all doses of methylprednisolone, while neutrophil chemotaxis was more evident with intermediate and high doses of methylprednisolone. Considering dose-related side effects of methylprednisolone, this study suggested the intermediate dose of methylprednisolone to reduce brain death-induced inflammatory responses in donors' lungs[63]. These findings need human studies before extrapolation to routine clinical use.

\section{Organ perfusate solutions}

Animal studies have shown decreased generation of pro-inflammatory cytokines, IRI and donated tissues edema by adding (methyl)prednisolone to perfusate STEEN and Perfadex solutions for heart and lung grafts [64, 65]. Recently, normothermic ex vivo heart perfusion using the Transmedics organ care system (OCS) has been used clinically for preservation of hearts donated after circulatory death. Based on Transmedic OCS protocol, methylprednisolone is added to the perfusate solution to reduce IRI and preserve cardiac function[66].

\section{Disadvantages of GCs in SOT}

The main drawback of GCs is their diverse adverse effects on various tissues. Side effects are usually related to genomic mechanism of action of these drugs, mainly transactivation ones; therefore, these side effects usually have prolonged onset and are associated with cumulative dose of GC over the duration of its administration ${ }^{[1,5,6]}$. Another aspect that should be considered especially in SOT patients is drug interactions of GCs with other drugs in these patients. These aspects are briefly reviewed below.

\section{Side effects}

\subsection{Infections}

Glucocorticoids increase the risk of bacterial, fungal, and viral infections [6]. A multivariate regression analysis on data of 45164 kidney transplant recipients in 20002011 from United States Renal Data System (USRDS) showed that steroid-free immunosuppressive regimen was associated with reduced risk of pneumonia (adjusted $\mathrm{HR}=0.89 ; \mathrm{P}=0.002$ ) and sepsis (adjusted $\mathrm{HR}=0.80 ; \mathrm{P}<0.001$ ) ${ }^{[67]}$. A multicenter, case-control study on 988 episodes of Enterobacterale-induced blood stream infection among SOT patients showed that about $40 \%$ of these episodes are caused by extended-spectrum $\beta$ - 
lactamase (ESBL) producing organisms. Taking corticosteroid-containing immunosuppressive regimens was identified as a risk factor for ESBL-Enterobacterale induced blood stream infection (adjusted $\mathrm{OR}=1.3,95 \% \mathrm{CI}, 1.03-1.65 ; \mathrm{P}=0.03$ ) ${ }^{[68]}$. Nocardiosis is another bacterial infection reported among immunocompromised patients such as SOT recipients. A retrospective study compared 60 adult patients who were hospitalized with nocardiosis to a group of 120 patients which was randomly selected among hospitalized patients with community-acquired pneumonia. Multivariable logistic regression analyses showed that immunosuppressive therapy was positively associated with nocardiosis (matched $\mathrm{OR}=4.40$, 95\% CI 2.25-8.62; P<0.001). Among immunosuppressive therapy, GC therapy was a typical risk factor for nocardiosis (matched OR=4.69, 95\% CI 2.45-8.99; $\mathrm{P}<0.001$ ), especially for pulmonary nocardiosis (matched OR=5.90, 95\% CI 2.75-12.66; P < 0.001). The positive association between solid organ transplantation and nocardiosis was mitigated following adjustment for GC administration in a multivariable model. The association between taking GC and nocardiosis was stronger in patients with chronic pulmonary disease $(\mathrm{OR}=5.74,95 \% \mathrm{CI}$ 2.75-12.66; $\mathrm{P}<0.001)$ than in the pooled analysis of all nocardiosis cases ${ }^{69}$. Another analysis on 112 patients with nocardiosis, among them 67 were immunocompromised patients showed that pulmonary nocardiosis among immunocompromised patients was significantly associated with taking high dose GC. Immunocompromised patients showed more disseminated forms of infection, with the highest rate in SOT recipients, and had significantly higher mortality compared with immunocompetent patients[70].

Taking GCs is a risk factor for fungal infections including mucormycosis [71] and invasive Aspergyllosis ${ }^{[72,73]}$. Although American society of transplantation suggests re-initiation of Pneumocystis jirovecii pneumonia (PJP) prophylaxis with intensification of immunosuppression such as treatment of acute rejection with GCs[74], the association between GC bolus for acute rejection and PJP remains controversial[75]. While a French case control study exhibited that GC bolus administration for acute rejection in kidney transplant patients as an independent factor correlated with $\mathrm{PJP}[76]$ and a Korean study showed that taking GCs is significantly associated with PJP[77], a meta-analysis found that GCs injections for acute rejection did not increase the risk of PJP[75]. On the other hand, a retrospective case series showed that adding GCs to PJP treatment of non-HIV infected patients ( 3 of 28 were SOT patients) was associated with lower mortality [78], while an older retrospective study comparing PJP-infected non-HIV patients with or without adjunctive steroid therapy (12 of 59 patients in GC taking group and 14 of 29 patients in no GC group were SOT patients) found that GC use may not improve outcome of moderate to severe PJP in these patients ${ }^{[79] .}$

Regarding viral infections, it has been reported that prednisolone daily doses of $10 \mathrm{mg}$ or higher is associated with higher risk of respiratory viral infection[80]. Community acquired viral respiratory infections (rhinovirus followed by coronavirus and respiratory syncytial virus) has been reported in approximately $25 \%$ of lung transplant recipients during the first year after transplantation especially in those receiving nasal glucocorticoids[81]. Corticosteroid use is a risk factor for adenovirus infections including urinary tract infection with this virus $(\mathrm{OR}=3.86,95 \% \mathrm{CI} 1.21-12.24 ; \mathrm{P}=0.02$ for acquiring 
urinary tract infections) ${ }^{[82]}$. It has been reported that kidney transplant patients on the maintenance GCs are more likely to be admitted with COVID-19[83]. Some authors reported that one of the major risk factors associated with survival among kidney transplant patients infected with SRAS-CoV2 is receiving prednisolone, $(\mathrm{OR}=5.98,95 \%$ CI 1.65-21.60); $\mathrm{P}<0.01)^{[84]}$.

BK (polyoma) virus infection is common during 6 months after renal transplantation and may lead to BK virus associated nephropathy (BKVAN). There are case reports of BKVAN that resulted in native kidney failure in other types of SOT patients. Taking GCs pulse for the treatment of acute allograft rejection has been reported in these patients before BKVAN[85]. Causality assessment needs more studies.

Regarding cytomegalovirus (CMV) infection, a retrospective study evaluated 71 SOT patients during the same time period, among them 49 patients were tested for genotypic resistance CMV variants and 22 were not because of no clinical suspicion for resistance variants. This study compared the patients in 3 groups; group 1 were patients with resistant CMV infections (defined as document of failure to reach at least $1 \log _{10}$ decline in CMV DNA load after two weeks of treatment with (val)ganciclovir, foscarnet, cidofovir and at least $1 \mathrm{CMV}$ resistant genotypic mutation), group 2 refractory CMV infection (defined as documented failure to have $1 \log _{10}$ or more decline in CMV DNA level after at least two weeks of treatment with (val)ganciclovir), and group 3 (no suspected CMV resistance and not tested for that). Results showed that patients in group 1 and 2 were taking higher mean daily doses of prednisolone compared with patients in group 3 (10 $\mathrm{mg}$ a day or higher versus $5 \mathrm{mg}$ daily); however, in the final model, daily GC dose was not a significant risk factor for resistant or refractory CMV infection [86]. An experimental study indicated that GCs activate major immediate-early promoter (MIEP) which drives CMV gene expression. This GC effect is mediated via GR pathway and leads to reactivation of latent CMV from primary monocytes. To investigate the clinical relevance of this experimental finding, the same researchers retrospectively analyzed data of liver transplant patients and found that taking prednisolone as baseline immunosuppression and/or methylprednisolone as augmented immunosuppression can trigger CMV reactivation in intermediate-risk patients $(D+/ R+)$ to the levels comparable with high-risk patients (D+/R-) ${ }^{[87]}$.

One-year cumulative doses of $1830 \mathrm{mg}$ or more of GCs has been associated with TB infection in patients with systemic lupus erythematosus $(\mathrm{OR}=2.74,95 \%$ CI 1.26-5.98; $\mathrm{P}=0.011)^{[88]}$ that may be true for SOT patients as well.

Severe Sterongyloides stercolaris infection is associated with high morbidity and mortality among kidney transplant patients and is usually accompanied with gastrointestinal and respiratory symptoms. A multicenter cohort study consisting 46 kidney transplant patients with severe Sterongyloides stercolaris infection and 92 matched control patients found that cumulative GC dose was an independent risk factor for severe Sterongyloides stercolaris infection [median (IQR) of doses of $73.32(40.93-157.46) \mathrm{mg} / \mathrm{kg}$ in the case group versus $65.23(32.05-155.28) \mathrm{mg} / \mathrm{kg}$ in controls) $(\mathrm{OR}=1.005,95 \% \mathrm{CI}: 1.001-1.009 ; \mathrm{P}=$ 
$0.008)^{[89]}$. As seen, the calculated OR is approximately 1 , which may not be of clinical importance despite statistical significance.

Although rare, visceral leshmaniasis may occur after solid organ transplantation relating to general prevalence of this parasite in that geographic area. High dose prednisolone within preceding 6 months has been associated with this infection in SOT patients ${ }^{[00]}$.

\subsection{Bone disorders}

GCs antagonize the effects of vitamin D, decrease intestinal absorption of calcium, inhibit secretion of growth hormone, inhibit bone formation (by inhibiting osteoblasts differentiation and increasing their apoptosis), increase bone resorption (by enhancing osteoclasts formation), and finally lead to osteoporosis and increased risk of fractures especially in trabecular bones[ ${ }^{[6]}$. Chronic kidney disease-mineral bone disorder (CKDMBD) after kidney transplantation is a mix of pre-existing disorders and new alterations. The final results are abnormal mineral metabolism (hypercalcemia and hypophosphatemia) and bone changes (high or more commonly low bone turnover disease) with consequences of decreased bone mineral density and increased risk of bone fractures ${ }^{[91]}$. Although not completely clarified, several factors play roles in posttransplant bone disorders such as immunosuppressive treatment especially corticosteroids, persistently high levels of PTH, vitamin D deficiency, and hypophosphatemia. Transplant recipients are at four-fold higher risk of fracture compared with general population. One of the most relevant risk factors is high doses or prolonged GC therapy [91, 92]. Kidney transplant recipients with early steroid withdrawal showed higher bone mineral density in lumbar spine and femoral neck and less osteopenia[93]. On the other hand, one study followed 36 renal transplant patients who continued low daily dose of $5 \mathrm{mg}$ prednisolone from day 42 after transplantation onward for 1 year. None of these patients received any treatment for bone disorders. In addition to bone mass densitometry, novel bone quality parameters including trabecular bone score and bone material strength index were evaluated for these patients. Findings indicated small decrease in bone mineral density in femoral neck at 3-months and in lumbar spine at 12-months after transplantation, while, no changes in trabecular bone score and bone material strength index were found, showing limited effects of low daily doses of GCs on bone ${ }^{[94]}$. Osteonecrosis of the hip is another side effects of corticosteroids in SOT patients[95]. Although some studies showed that cumulative dose of methylprednisolone/prednisolone after kidney transplantation has been a risk factor for avascular osteonecrosis [96, 97], a meta-analysis found little correlation between cumulative doses and duration of administration of methylprednisolone/prednisolone and avascular osteonecrosis of femoral head[98].

\subsection{Growth in pediatric transplant recipients}

By inducing abnormal growth hormone secretion and response, GCs impair stature growth in children and prepubertal adolescence ${ }^{[6]}$. In contrast, GR in hepatocytes is essential for postnatal body growth by mediating the growth hormone signaling in mice[99]. New animal data also suggests that GCs decrease longitudinal bone growth by 
upregulation of fibroblast growth factor-23 (FGF23) and its receptor (FGF23R3) expression[100]. GC-induced growth retardation in pediatric transplant patients encouraged SOT teams to apply steroid minimization protocols in prepubertal kidney transplant patients with better bone health, growth outcome and comparable allograft rejection rates ${ }^{[14,101,102]}$.

\subsection{Metabolic complications and cardiovascular risks}

Obesity and metabolic syndrome with three components of hyperglycemia, hyperlipidemia, and hypertension, are common long-term side effects of GCs; these adverse effects increase atherogenesis and the risk of cardiovascular events[6]. Adipocyte GR deficiency promotes adipose tissue expandability and improves the metabolic profile during GC exposure ${ }^{[103]}$. In contrast, GR in cardiomyocytes is essential in cardio protection; deletion of cardiomyocyte GR increases mortality due to the development of spontaneous cardiac pathology in both male and female mice[104]. The mechanism of GCinduced hyperglycemia is insulin resistance followed by increased hepatic gluconeogenesis ${ }^{[1]}$. Post-transplant diabetes mellitus (PTDM) is associated with higher risk of mortality and graft loss ${ }^{[105]}$. PTDM incidence in SOT patients varies from $10 \%$ to $74 \%$ depending on the country and ethnicity of the patients and diagnostic criteria ${ }^{[105-107]}$. There are several risk factors for PTDM such as viral infections, underlying kidney diseases, and different immunosuppressive drugs that can confound causality assessment between steroid dose and duration and PTDM in SOT patients ${ }^{[1]}$. A Malaysian study of 168 patients without diabetes before transplantation showed the PTDM incidence of $17 \%$ during one year after renal transplantation. In that study, daily prednisolone dose was not associated with the development of PTDM[107]. Another 4-year follow-up study on 400 kidney transplant patients without history of diabetes before transplantation (96 patients on steroid-free and 304 patients on $5 \mathrm{mg}$ /day prednisolone in immunosuppressive regimen) indicated that taking $5 \mathrm{mg}$ daily prednisolone was associated with a small but not statistically significant increase in $\mathrm{HbA1c}$ and significantly higher risk of prediabetes $(\mathrm{RR}=1.789 ; 95 \% \mathrm{CI} 1.007-3.040 ; \mathrm{P}=0.026)$ but not PTDM compared with steroid withdrawal regimen. Although other components of immunosuppressive regimen such as the type of CNI (tacrolimus versus cyclosporine A) can affect PTDM risk, in the multivariate analysis of Tillmann's study, independent of the higher risk of tacrolimus compared with cyclosporine in inducing PTDM, higher risk of prediabetes with long-term low dose steroid was shown ${ }^{[108]}$. On the other hand, a metaanalysis on more than 22 thousand kidney transplant patients showed that early steroid withdrawal during 1 week after transplantation is associated with less PTDM risk $(\mathrm{RR}=0.91 ; 95 \% \mathrm{CI} 0.37-0.97 ; \mathrm{P}=0.04)^{[10]}$. Association between new onset hyperglycemia and GC-containing maintenance immunosuppression among liver transplant recipients is controversial[109, 110]. While a Japanese retrospective analysis on 461 adult liver transplant recipients from living donors did not find any association between taking GC and PTDM[109], a randomized clinical trial on live donor liver transplant patients reported significantly higher incidences of PTDM among patients taking steroids versus steroidfree group during 3- and 6-months follow-ups ${ }^{[110]}$. One confounding factor in data 
interpretation is using different diagnostic criteria for PTDM in different studies. For example, in Toshima et al study, fasting plasma glucose of $110 \mathrm{mg} / \mathrm{dL}$ or higher has been used as a cut-off for PTDM definition[109], while based on standard criteria of American Diabetes Association, plasma glucose level of $126 \mathrm{mg} / \mathrm{dL}$ or higher is defined as diabetes ${ }^{[111]}$.

Hyperlipidemia is another known metabolic side effect of GCs. Increased total cholesterol, very low-density lipoprotein (VLDL) cholesterol, and triglyceride levels and decreased HDL-cholesterol concentration have been reported with GCs, depending on the dose and duration of their administration [6]; however, a large US cohort study showed beneficial effect of GCs on increasing HDL cholesterol among population older than 65 years old [112]. Wide ranges of mechanisms have been supposed for GC effects on lipid profile including increased activity of acetyl-Coenzyme A carboxylase and free fatty acids synthetase and enhanced hepatic synthesis of VLDL, inhibition of lipoprotein lipase, alteration in insulin signal pathway, and possible inhibition of the activity of 3-hydroxy3-methylglutaryl Coenzyme A (HMG-CoA) reductase[6]. The latter mechanism theoretically can have positive effects on lipid profile that may explain some controversies regarding GC-induced lipid changes in the literature. Regarding organ transplant patients, a study on liver transplant recipients showed that taking maintenance GCs was an independent factor associated with hyperlipidemia but not with the two other component of metabolic syndrome (hyperglycemia and hypertension) in this patient population ${ }^{[109]}$. In contrast, another study that compared steroid-free versus steroid-taking immunosuppressive regimens in living donor liver transplant recipient, found significant higher incidences of all components of metabolic syndrome including new onset hyperglycemia, new-onset hypertension, and hypertriglyceridemia among steroid-taking group ${ }^{[110]}$.

Although the effect of steroid withdrawal on hypertension after transplantation is controversial, a study on pediatric liver transplant patients that followed the patients with ambulatory blood pressure monitoring showed improved blood pressure especially nocturnal hypertension and restoring circadian rhythm of blood pressure after GC discontinuation in these patients ${ }^{[113]}$. A Saudi study on adult kidney transplant patients showed that steroid-sparing patients had significantly lower weigh gain and a nonstatistically significant better blood pressure and lipid control[114]. Different mechanisms have been reported for GC-induced arterial hypertension including salt and water retention by activating renal mineralocorticoid receptor (MR) and regulating vascular activity by activating GR in endothelial and vascular smooth muscle cells. Interestingly, GR in vascular endothelial cells is required for dexamethasone-induced hypertension[115], while loss of endothelial GR increases hemodynamic instability, inflammation, and mortality in sepsis, and GR deficiency in endothelial cells prevents the therapeutic protection by dexamethasone after LPS treatment $[116,117]$. Hypertension is more common among patients taking daily doses of more than $20 \mathrm{mg}$ prednisolone. Metabolic changes and hypertension increase atherogenesis and risk of cardiovascular events in long-term GC taking patients ${ }^{[6]}$. 


\subsection{Neuropsychiatric side effects}

Most immunosuppressive drugs especially CNIs, glucocorticoids and mTOR inhibitors can induce neurologic side effects. Sometimes the assessment of causality is hard and all drugs work together to manifest the side effect(s). Glucocorticoids easily pass the blood brain barrier and reach all brain cells and result in HPA axis suppression, neuropsychiatric and neurodegenerative side effects. Prolonged exposure to glucocorticoids in SOT patients and high GC doses and concentrations (e.g. during treatment of acute rejection) increase the risk of neuropsychiatric side effects because of structural remodeling in neurons, synoptic loss, and maladaptive alterations in glial function[118]. GCs cause different neurologic side effects such as headache, tremor, seizure, stroke, and pseudotumor cerebri. GC-induced psychiatric adverse effects vary from minor mood changes and confusion, sleep disorders, anxiety to severe psychotic features ${ }^{[6,118]}$.

\subsection{Muscular side effects}

GCs has catabolic effects on muscles, leading to muscular atrophy, cramping and progressive symmetrical muscle deficit. They can induce acute or chronic myopathy. Tendon rupture is a rare side effect of GCs ${ }^{[6]}$. High doses of GCs cause muscular atrophy via activating GR in the muscle[119].

\subsection{Adrenal insufficiency}

Suppression of the activity of HPA axis and the subsequent adrenal insufficiency are well-known side effects of GCs. Adrenal insufficiency may be potentially life-threatening because of the risk of acute adrenal crisis. A study on renal transplant patients treated with oral prednisolone at daily doses of 5 to $7.5 \mathrm{mg}$ for 6 months or more found insufficient adrenal response to synacthen test in about $43 \%$ of the patients which shows high prevalence of adrenal insufficiency due to long-term low dose GCs in these patients[120].

In addition to decrease in endogenous GC production, exogenous GC such as prednisolone may also enhance the activity of $11 \beta$-hydroxysteroid dehydrogenase type 1 (11 $\beta$-HSD1), the enzyme that is responsible for regeneration of cortisol from inactive metabolite, cortisone. A cohort study investigated this hypothesis in prednisolonetreated kidney transplant patients compared with healthy controls. The median daily dose of prednisolone in these patients was $10 \mathrm{mg}$ (IQR of 7.5-10mg). 24-hour urinary cortisol, cortisone, tetrahydrocorisol (THF), allotetrahydrocortisol (alloTHF), and tetrahydrocortisone (THE) were measured. Twenty-four-hour urinary excretion of cortisol and its metabolites were used as measures of endogenous glucocorticoid production, while (THF + alloTHF)/THE and cortisol/cortisone ratios were used as reflectors of 11 $\beta$-HSD1 activity. Findings revealed that urinary cortisol and metabolite excretion were significantly lower (indicating reduced endogenous cortisol synthesis), while (THF + alloTHF)/THE and cortisol/cortisone ratios were significantly higher (indicating increased 11 $\beta$-HSD1 activity) in kidney transplant recipients compared with 
healthy controls. Daily doses of prednisolone had significant inverse association with reduced endogenous cortisol synthesis and significant, positive association with markers of $11 \beta$-HSD1 activity. Such changes in endogenous GC production and regeneration were associated with increased risk of mortality in kidney transplant patients even after adjustment for confounders such as patients' age, gender, estimated glomerular filtration rate, C-reactive protein, body surface area, and daily doses of prednisolone ${ }^{[121]}$. Some researchers found significant associations between HPA suppression and higher prevalence of metabolic syndrome and its individual components (central obesity, dyslipidemia, hypertension, and hyperglycemia) in kidney transplant patients taking prednisolone ${ }^{[122]}$.

\subsection{Gastrointestinal side effects}

Gastrointestinal side effects of GCs include peptic ulcers, upper gastrointestinal bleeding, pancreatitis, diverticular perforation, and colonic malakoplakia (a chronic granulomatous disease) ${ }^{[123]}$.

Immunosuppressive therapy after solid organ transplantation may change gut microbiota and be associated with increased rates of overall and infection-related mortality, rates of all infections including nosocomial infections, duration of infections, infections complications, rejection rates and graft loss. Some studies tried to differentiate the effect of different types of immunosuppressive drugs that are used in combination in SOT patients. Regarding corticosteroids, a study on liver transplanted mice showed that prednisolone administration reduces the concentration of Bacteroidetes while increases the concentration of Firmicutes in the feces. In that study, prednisolone in combination with mycophenolate and tacrolimus increased E. Coli colonization. Serial testing of fecal samples of kidney transplant recipients revealed that compared to those remaining on maintenance corticosteroid, patients with early GC withdrawal had numerically, but not statistically significant, lower Clostridiales and Erysipelotrichales ${ }^{[124]}$.

\subsection{Dermatologic effects}

Cushingoid appearance; facial erythrosis; skin thinning; rosacea and acne that may rarely progress to nodulocystic transformation; impaired wound healing; purpura after minor trauma; hirsutism; and striae rubrae are dermatologic side effects of GCs that are usually dose- and treatment duration dependent ${ }^{[6]}$.

\subsection{Other complications}

GCs increase the risk of thrombosis due to endothelial damage and inducing hypercoaguable state and stasis ${ }^{[6]}$. Posterior subcapsular cataract and glaucoma are doserelated ophthalmologic side effects of $\mathrm{GCs}^{[6]}$. Hernia occurrence is common after liver transplantation and attributed to several factors, one of them is taking steroid[125].

A retrospective analysis on surgery complications of 382 patients with metabolic and bariatric surgery and prior history of SOT showed that while taking GCs are associated with 2 folds increase in overall morbidity, it was not contributed to morbidities related to bariatric surgery[126]. 
Pretransplant administration of GCs in patients with idiopathic pulmonary fibrosis may decrease graft survival after lung transplantation compared with GC-free patients ${ }^{[127]}$. Although concerns have been arisen regarding airway anastomotic complications after lung transplantation in patients who were treated with GCs before transplantation, a retrospective study on 66 double lung transplant recipients ( 40 were steroid user before transplantation) showed that early development of airway complications was not significantly higher in patients who took steroids before lung transplantation. In addition, in preoperative steroid users the dose of steroid was not associated with the rate of posttransplant airway complications ${ }^{[128]}$.

\section{Drug-drug interactions}

GCs are primarily metabolized by CYP450 3A4 isoenzyme and are also substrates for energy-dependent efflux pump, P-glycoprotein [123, 129]. GC metabolism may or may not be affected by CYP450 3A4 inhibitors such as macrolide antibiotics, azole antifungal medications, and protease inhibitors. Studies have shown decreased clearance of methylprednisolone but not prednisolone with co-administration of CYP3A4 inhibitors[130, 131]. CYP450 3A4 inducers (rifampin, carbamazepine, phenobarbital, phenytoin) can decrease GC's serum levels ${ }^{[29]}$. GCs can induce CYP450 3A4/5 isoenzymes ${ }^{[129]}$ and therefore, increase the metabolism of CNIs (cyclosporine and tacrolimus) as the substrates of CYP450 3A4/5[132]. Clinical studies showed significant increase in dose-adjusted tacrolimus blood levels in patients on GC withdrawal regimens compared with patients taking GC-containing maintenance immunosuppression [132]. Interactions between GCs and tacrolimus are more seen in patients carrying CYP3A5 ${ }^{*} 1$ allele[133]. GCs significantly contributes to inter-individual variability of apparent clearance of oral tacrolimus ${ }^{[134]}$. On the other hand, some studies reported that cyclosporine decreases prednisolone clearance by $25-30 \%$ in kidney transplant patients $[135]$, while others found no difference in dose-adjusted exposure of prednisolone when co-administered with cyclosporine or tacrolimus [136].

\section{Possible need for therapeutic drug monitoring}

Prednisolone is a standard component of most immunosuppressive protocols after solid organ transplantation. Therapeutic drug level monitoring is not usually done for GCs. A study evaluated the pharmacokinetic characteristics of prednisolone, prednisone, and also cortisol and cortisone profiles, after treatment with prednisolone in adult kidney transplant recipients in the early 8-week post-transplant period. Blood samples were obtained predose and during a 24-hour dose interval. Findings showed that renal transplant recipients experienced a relatively high prednisolone exposure, in parallel with strong suppression of endogenous cortisol profile as confirmed by a low eveningto-morning ratio of cortisol. A significant negative correlation $(\mathrm{r}=-0.83)$ between prednisolone AUC0-24 and morning cortisol concentrations was seen. AUC0-24 of prednisolone and cortisol varied 3-fold and 18 -fold, respectively among patients. These results reveal large inter-individual variability in both prednisolone exposure and 
suppression of endogenous cortisol that signify a possible need for therapeutic drug monitoring of GCs $[137]$.

\section{Summary and perspective}

GCs have been the mainstay for SOT for decades due to GC's potent anti-inflammatory and immunosuppressive effects on the innate immunity and the significant tissue protective effects of GR on liver, kidney, and heart. In contrast, many of the side effects of GCs are on the non-target organs/tissues, such as bone, neuromuscular, adipose tissue, GI tract, and skin. Thus, specific delivery of GCs, via nanoparticles or transportermediated prodrugs, to the target organs of liver, kidney, and/or heart will enhance the efficacy and decrease the side effects of GCs in SOT. GCs' side effects are generally associated with long-term use of high doses of GCs. It is noteworthy that most GCs activate both GR and MR. Recent studies indicate that some of the side effects of GCs on the heart, kidney, and adipose tissues may be due to the activation of MR by GCs ${ }^{[138-141]}$. Therefore, GCs with higher selectivity for GR over MR, such as dexamethasone and budesonide, may have less side effects in SOT patients ${ }^{[23,142]}$. Additionally, GCs' metabolic actions can be modulated by AMP-activated protein kinase (AMPK), a master regulator of energy metabolism. Activation of AMPK increased the phosphorylation of GR at Serine-211 and reversed GC-induced hepatic steatosis and suppressed GCmediated stimulation of glucose production in rats[143]. Interestingly, impaired AMPK activity was associated with steatotic graft injury in patients with living donor liver transplantation ${ }^{[144]}$. Thus, whether AMPK activators can ameliorate the metabolic side effects of GCs in SOT warrants investigation. In conclusion, approaches that enhance GC's GR selectivity, increase target-tissue-specific delivery of GCs, and ameliorate the metabolic side effects of GCs will increase the efficacy and decrease the side effects of GCs in SOT.

Conflict-of-interest statement: Authors declare no conflict of interest for this article.

\section{References}

1 De Lucena DD, Rangel É B. Glucocorticoids use in kidney transplant setting. Expert Opini Drug Metab Toxicol 2018; 14: 1023-1041 [PMID:30265586 DOI: 10.1080/17425255.2018.1530214]

2 Nazzal M, Lentine KL, Naik AS, Ouseph R, Schnitzler MA, Zhang Z, Randall H, Dharnidharka VR, Segev DL, Kasiske BL, Hess GP, Alhamad T, McAdamsDemarco M, Axelrod DA. Center-driven and clinically driven variation in us liver transplant maintenance immunosuppression therapy: A national practice patterns analysis. Transplant Direct 2018; 4: e364 [PMID:30046654 DOI: 10.1097/txd.0000000000000800]

3 Goldraich LA, Stehlik J, Cherikh WS, Edwards LB, Urban R, Dipchand A, Ross HJ. Duration of corticosteroid use and long-term outcomes after adult heart transplantation: A contemporary analysis of the international society for heart and 
lung transplantation registry. Clinical Transplant 2018; 32: e13340 [PMID:29956385 DOI: $10.1111 /$ ctr.13340]

4 Sitruk L, Couchoud C, Hourmant M, Tuppin P, Macher MA, Legeai C. Description of immunosuppressive maintenance treatments post kidney transplant through the national system of health insurance. Nephrol Ther 2018; 14: 523-530 [PMID:29887268 DOI: 10.1016/j.nephro.2018.03.004]

5 Zaza G, Leventhal J, Signorini L, Gambaro G, Cravedi P. Effects of antirejection drugs on innate immune cells after kidney transplantation. Front Immunol 2019; 10: 2978 [PMID:31921213 DOI: 10.3389/fimmu.2019.02978]

6 Ponticelli C, Glassock RJ. Prevention of complications from use of conventional immunosuppressants: A critical review. J Nephrol 2019; 32: 851-870 [PMID:30927190 DOI: 10.1007/s40620-019-00602-5]

7 Panettieri RA, Schaafsma D, Amrani Y, Koziol-White C, Ostrom R, Tliba O. Nongenomic effects of glucocorticoids: An updated view. Trend Pharmacol Sci 2019; 40: 38-49. [PMID:30497693 DOI: 10.1016/j.tips.2018.11.002]

8 Eddy JL, Krukowski K, Janusek L, Mathews HL. Glucocorticoids regulate natural killer cell function epigenetically. Cell Immunol 2014; 290: 120-130 [PMID:24978612 DOI: 10.1016/j.cellimm.2014.05.013]

9 Vock DM, Matas AJ. Rapid discontinuation of prednisone in kidney transplant recipients from at-risk subgroups: An optn/srtr analysis. Transplant Int 2020; 33: 181-201 [PMID:31557340 DOI: 10.1111/tri.13530]

10 Song TR, Jiang YM, Liu JP, Wang ZL, Zeng J, Huang ZL, Fan Y, Wang XD, Lin T. Steroid withdrawal or avoidance is safe in high-risk kidney transplants: A systematic review and meta-analysis. Kaohsiung J Med Sci 2019; 35: 350-357 [PMID:30942560 DOI: 10.1002/kjm2.12064]

11 Fairfield C, Penninga L, Powell J, Harrison EM, Wigmore SJ. Glucocorticosteroidfree versus glucocorticosteroid-containing immunosuppression for liver transplanted patients. Cochrane Database Syst Rev 2015: CD007606. [PMID:26666504 DOI:10.1002/14651858.CD007606.pub3]

12 Pelletier SJ, Nadig SN, Lee DD, Ammori JB, Englesbe MJ, Sung RS, Magee JC, Fontana RJ, Punch JD. A prospective, randomized trial of complete avoidance of steroids in liver transplantation with follow-up of over 7 years. HPB 2013; 15: 286293. [PMID:23458449 DOI: 10.1111/j.1477-2574.2012.00576.x.]

13 Kasiske BL, Chakkera HA, Louis TA, Ma JZ. A meta-analysis of immunosuppression withdrawal trials in renal transplantation. J Am Soc Nephrol 2000; 11: 1910-1917 [PMID:11004223 DOI:10.1681/ASN.V11101910]

14 Tönshoff B, Tedesco-Silva H, Ettenger R, Christian M, Bjerre A, Dello Strologo L, Marks SD, Pape L, Veldandi U, Lopez P, Cousin M, Pandey P, Meier M. Threeyear outcomes from the cradle study in de novo pediatric kidney transplant recipients receiving everolimus with reduced tacrolimus and early steroid withdrawal. Ame J Transplant 2021; 21: 123-137 [PMID:32406111 DOI: 10.1111/ajt.16005] 
15 Nanmoku K, Kurosawa A, Kubo T, Shinzato T, Shimizu T, Kimura T, Yagisawa T. Conversion from steroid to everolimus in maintenance kidney transplant recipients with posttransplant diabetes mellitus. Exp Clin Transplant 2019; 17: 4751 [PMID:29911959 DOI: 10.6002/ect.2017.0178]

16 Montero N, Webster AC, Royuela A, Zamora J, Crespo Barrio M, Pascual J. Steroid avoidance or withdrawal for pancreas and pancreas with kidney transplant recipients. Cochrane Database Syst Revi 2014, CD007669 [PMID:25220222 DOI: 10.1002/14651858.CD007669.pub2]

17 Lamour JM, Mason KL, Hsu DT, Feingold B, Blume ED, Canter CE, Dipchand AI, Shaddy RE, Mahle WT, Zuckerman WA, Bentlejewski C, Armstrong BD, Morrison Y, Diop H, Iklé DN, Odim J, Zeevi A, Webber SA. Early outcomes for low-risk pediatric heart transplant recipients and steroid avoidance: A multicenter cohort study (clinical trials in organ transplantation in children - CTOTC-04). J Heart Lung Transplant 2019; 38: 972-981[PMID:31324444 DOI: 10.1016/j.healun.2019.06.006]

18 Bird AD, McDougall AR, Seow B, Hooper SB, Cole TJ. Glucocorticoid regulation of lung development: Lessons learned from conditional gr knockout mice. Mol Endocrinol 2015; 29: 158-171 [PMID:25535891 DOI: 10.1210/me.2014-1362]

19 Yamamoto H, Sugimoto S, Tanaka S, Kurosaki T, Otani S, Yamane M, Taira N, Oto $\mathrm{T}$, Toyooka S. A single-nucleotide polymorphism in a gene modulating glucocorticoid sensitivity is associated with the decline in total lung capacity after lung transplantation. Surg Today 2019; 49: 268-274 [PMID:30229311 DOI: 10.1007/s00595-018-1717-9]

20 Kim WR, Lake JR, Smit JM, Schladt DP, Skeans MA, Noreen SM, Robinson AM, MillerE, Synder JJ, Israni AK, Kasiske BL. Optn/srtr 2017 annual data report: Liver. Am J Transplant 2019; 19: 184-283. [PMID:30811890 DOI: 1.1111/ajt.15276]

21 Aberg F. Role of budesonide in liver transplantation. Transpl Immunol 2014; 30: 178-179. [PMID:24727087 DOI: 10.1016/j.trim.2014.03.004]

22 Zandieh I, Krygier D, Wong V, Howard J, Worobetz L, Minuk G, Witt-Sullivan H, Yoshida EM. The use of budesonide in the treatment of autoimmune hepatitis in canada. Can J Gastroenterol 2008; 22: 388-392. [PMID:18414714 DOI: 10.1155/2008/509459]

23 Bari K, Shah SA, Kaiser TE, Cohen RM, Anwar N, Kleesattel D, Sherman KE. Safety and efficacy of budesonide for liver transplant immune suppression: Results of a pilot phase 2a trial. Liver Transpl 2020; 26: 1430-1440 [PMID:32602616 DOI: 10.1002/lt.25837]

24 Brennan D. Kidney transplantation in adults: treatment of acute t-cell mediated (cellular) rejectionof therenal allograft; 2021 [cited 2021 Mar 15]. Database:uptodate. Availbale from: www.uptodate.com.

25 Djamali A. Kidney transplantation in adults: prevention and treatment of antibody-mediated rejection of the allograft. 2021 [cited 2021 Mar 15]. Database:uptodate. Availbale from: www.uptodate.com. 
26 Cotler SJ. Liver transplantaion in adults: treatment of acute $t$ cell mediated (cellular) rejection of the liver allograft. 2021 [cited 2021 Mar 15]. Database:uptodate. Availbale from: www.uptodate.com.

27 Eisen HJ. Heart transplantation in adults: treatment of acute allograft rejection. 2021 [cited 2021 Mar 15]. Database:uptodate. Availbale from: www.uptodate.com.

28 Pilewski J. Evaluation and treatment of acute lung transplant rejection. 2021 [cited 2021 Mar 15]. Database:uptodate. Availbale from: www.uptodate.com.

29 Chen J, Ferreira J, Martinez M, Lobritto S, Goldner D, Vittorio J. Role of budesonide for the treatment of rejection in pediatric liver transplantation. J Pediatr Gastroenterol Nutr 2020; 71: 388-392 [PMID:32404767 DOI: 10.1097/mpg.0000000000002784]

30 Parker A, Bowles K, Bradley JA, Emery V, Featherstone C, Gupte G, Marcus R, Parameshwar J, Ramsay A, Newstead C; Haemato-oncology Task Force of the British Committee for Standards in Haematology and British Transplantation Society. Management of post-transplant lymphoproliferative disorder in adult solid organ transplant recipients-bcsh and bts guideline. Br J Haematol 2010; 149: 693-705. [PMID:20408848 DOI: 10./1111/j.1365-2141.2010.08160.x.]

31 Nguyen LS, Ortuno S, Lebrun-Vignes B, Johnson DB, Moslehi JJ, Hertig A, Salem JE. Transplant rejections associated with immune checkpoint inhibitors: A pharmacovigilance study and systematic literature review. Eur J cancer 2021; 148: 36-47 [PMID:33721705 DOI: 10.1016/j.ejca.2021.01.038]

32 Tsung I, Worden FP, Fontana RJ. A pilot study of checkpoint inhibitors in solid organ transplant recipients with metastatic cutaneous squamous cell carcinoma. Oncologist 2021; 26: 133-138 [PMID:32969143 DOI: 10.1002/onco.13539]

33 Engberg H, Wehberg S, Bistrup C, Heaf J, Sørensen SS, Thiesson HC, Hansen JM, Svensson M, Green A, Marckmann P. Cancer risk and mortality after kidney transplantation: A population-based study on differences between danish centres using standard immunosuppression with and without glucocorticoids. Nephrol Dial Transplant 2016; 31: 2149-2156 [PMID:27587604 DOI: 10.1093/ndt/gfw304]

34 Sørensen HT, Mellemkjaer L, Nielsen GL, Baron JA, Olsen JH, Karagas MR. Skin cancers and non-hodgkin lymphoma among users of systemic glucocorticoids: A population-based cohort study. J Natl Cancer Inst 2004; 96: 709-711 [PMID:15126608 DOI: $10.1093 /$ jnci/djh118]

35 Allen PJ, Chadban SJ, Craig JC, Lim WH, Allen RDM, Clayton PA, Teixeira-Pinto A, Wong G. Recurrent glomerulonephritis after kidney transplantation: Risk factors and allograft outcomes. Kidney Int 2017; 92: 461-469 [PMID:28601198 DOI: 10.1016/j.kint.2017.03.015]

36 Di Vico MC, Messina M, Fop F, Barreca A, Segoloni GP, Biancone L. Recurrent iga nephropathy after renal transplantation and steroid withdrawal. Clin Transplant 2018; 32: e13207 [PMID:29345747 DOI: 10.1111/ctr.13207]

37 Hansrivijit $\mathbf{P}$, Ghahramani N. Combined rituximab and plasmapheresis or plasma exchange for focal segmental glomerulosclerosis in adult kidney transplant 
recipients: A meta-analysis. Intl Urol Nephrol 2020; 52: 1377-1387 [PMID:32306197 DOI: $10.1007 /$ s11255-020-02462-6]

38 Lim WH, Shingde M, Wong G. Recurrent and de novo glomerulonephritis after kidney transplantation. Front Immunol 2019; 10: 1944 [PMID:31475005 DOI: 10.3389/fimmu.2019.01944]

39 Infante B, Rossini M, Di Lorenzo A, Coviello N, Giuseppe C, Gesualdo L, Giuseppe G, Stallone G. Recurrence of immunoglobulin a nephropathy after kidney transplantation: A narrative review of the incidence, risk factors, pathophysiology and management of immunosuppressive therapy. Clin Kidney J 2020; 13: 758-767 [PMID:33123355 DOI: 10.1093/ckj/sfaa060]

40 Faisal N, Renner EL. Recurrence of autoimmune liver disease after transplantation. World J Hepatol 2015; 7: 2896-2905. [PMID:26689244 DOI: 10.4254/wjh.i29.2896]

41 Czaja AJ. Diagnosis, pathogenesis, and treatment of autoimmune hepatitis after liver transplantation. Dig Dis Sci 2012; 57: 2248-2266 [PMID:22562533 DOI: 10.1007/s10620-012-2179-3]

42 Freist M, Bertrand D, Bailly E, Lambert C, Rouzaire PO, Lemal R, Aniort J, Büchler $\mathrm{M}$, Heng AE, Garrouste C. Management of immunosuppression after kidney transplant failure: Effect on patient sensitization. Transplant Proceed 2021; 53: 962969 [PMID:33288310 DOI: 10.1016/j.transproceed.2020.10.009]

43 Miller WM, Karus MA, Brennan DC. Kidney transplantation in adults: Management of the patient with a failed kidney transplant. 2021 [cited 2021 Mar 15]. Database:uptodate. Availbale from: www.uptodate.com.

44 Zhao XF, Lin DD, Li N, Wu JS, Guo QL, Wang L. Diagnosis and treatment of acute graft-versus-host disease after liver transplantation: A report of 11cases. Transpl Immunol 2020; 62: 101307 [PMID:32540505 DOI: 10.1016/j.trim.2020.101307]

45 Kanthasamy K, Chang MT, Kaur M. Graft-vs-host disease colitis after lung transplant. ACG case Rep J 2019; 6: e00287 [PMID:32309482 DOI: 10.14309/crj.0000000000000287]

46 Yang J, Yang L, Wu L, Zhao Q, Chen M, He X. Efficacy and safety of steroid therapy for posttransplant hyperbilirubinemia caused by early allograft dysfunction: A randomized controlled trial. Med Sci Monit 2019; 25: 1936-1944 [PMID:30870403 DOI: 10.12659/msm.915128]

47 Ponticelli C, Moroni G. Fetal toxicity of immunosuppressive drugs in pregnancy. J Clin Med 2018; 7: [PMID:30558290 DOI: 10.3390/jcm7120552]

48 Sugimoto S, Miyoshi K, Kurosaki T, Otani S, Yamane M, Kobayashi M, Oto T. Favorable survival in lung transplant recipients on preoperative low-dose, as compared to high-dose corticosteroids, after hematopoietic stem cell transplantation. Int J Hematol 2018; 107: 696-702 [PMID:29383622 DOI: 10.1007/s12185-018-2417-3]

49 Jiang S, Prozeller D, Pereira J, Simon J, Han S, Wirsching S, Fichter M, Mottola M, Lieberwirth I, Morsbach S, Mailänder V, Gehring S, Crespy D, Landfester K. Controlling protein interactions in blood for effective liver immunosuppressive 
therapy by silica nanocapsules. Nanoscale 2020; 12: 2626-2637 [PMID:31939969 DOI: 10.1039/c9nr09879h]

50 van Alem CMA, Schmidbauer M, Rong S, Derlin K, Schmitz J, Bräsen JH, Thorenz A, Chen R, Ruben JM, Winter EM, Schilperoort M, Kooijman S, Lalai RA, Metselaar JM, Klemann C, Meier M, van Kooten C, Gueler F, Rotmans JI. Liposomal delivery improves the efficacy of prednisolone to attenuate renal inflammation in a mouse model of acute renal allograft rejection. Transplantation 2020; 104: 744-753 [PMID:31929419 DOI: 10.1097/tp.0000000000003060]

51 Zhao Y, Shen XF, Cao K, Ding J, Kang X, Guan WX, Ding YT, Liu BR, Du JF. Dexamethasone-induced myeloid-derived suppressor cells prolong allo cardiac graft survival through inos- and glucocorticoid receptor-dependent mechanism. Front Immunol 2018; 9: 282 [PMID:29497426 DOI: 10.3389/fimmu.2018.00282]

52 Pratschke J, Wilhelm MJ, Kusaka M, Basker M, Cooper DK, Hancock WW, Tilney NL. Brain death and its influence on donor organ quality and outcome after transplantation. Transplantation 1999; 67: 343-348. [PMID:10030276 DOI: https:/ / doi.org/10.1097/00007890-199902150-00001]

53 De Vries DK, Lindeman JHN, Ringers J, Reinders M, Rabelink T, Schaapherder AFM. Donor brain death predisposes human kidney grafts to a proinflammatory reaction after transplantation. Am J Transplant 2011; 11: 1064-1070. [PMID:21449948 DOI: https://doi.org/10.1111/j.1600-6143.2011.03466.x]

54 Zhai Y, Petrowsky H, Hong JC, Busuttil RW, Kupiec-Weglinski JW. Ischaemiareperfusion injury in liver transplantation--from bench to bedside. Nat Rev Gastroenterol Hepatol 2013; 10: 79-89. [PMID:23229329 DOI: 10.1038/nrgastro.2012.225]

55 Sayed Zeid AS, Sayed SS. A comparative study of the use of dexamethasone, nacetyl cysteine, and theophylline to ameliorate renal ischemia-reperfusion injury in experimental rat models: A biochemical and immuno-histochemical approach. Saudi J Kidney Dis Transpl 2020; 31: 982-997 [PMID:33229761 DOI: 10.4103/13192442.301203]

56 Yang $\mathrm{X}, \mathrm{Wu} \mathrm{X}, \mathrm{Wu} \mathrm{K}$, Yang D, Li Y, Shi J, Liu Y. Correlation of serum- and glucocorticoid-regulated kinase 1 expression with ischemia-reperfusion injury after heart transplantation. Pediatr Transplant 2015; 19: 196-205 [PMID:25515054 DOI: $10.1111 /$ petr.12417]

57 Kotsch K, Ulrich F, Reutzel-Selke A, Pascher A, Faber W, Warnick P, Hoffman S, Francuski M, Kunert C, Kuecuek O, Schumacher G, Wesslau C, Lun A, Kohler S, Weiss S, Tullius SG, Neuhaus P, Pratschke J. Methylprednisolone therapy in deceased donors reduces inflammation in the donor liver and improves outcome after liver transplantation: A prospective randomized controlled trial. Ann Surg 2008; 248: 1042-1050 [PMID:19092349 DOI: 10.1097/SLA.0b013e318190e70c]

58 Kotloff RM, Blosser S, Fulda GJ, Malinoski D, Ahya VN, Angel L, Byrnes MC, DeVita MA, Grissom TE, Halpern SD, Nakagawa TA, Stock PG, Sudan DL, Wood KE, Anillo SJ, Bleck TP, Eidbo EE, Fowler RA, Glazier AK, Gries C, Hasz R, Herr 
D, Khan A, Landsberg D, Lebovitz DJ, Levine DJ, Mathur M, Naik P, Niemann CU, Nunley DR, O'Connor KJ, Pelletier SJ, Rahman O, Ranjan D, Salim A, Sawyer RG, Shafer T, Sonneti D, Spiro P, Valapour M, Vikraman-Sushama D, Whelan TP. Management of the potential organ donor in the icu: Society of critical care medicine/american college of chest physicians/association of organ procurement organizations consensus statement. Crit Care Med 2015; 43: 1291-1325 [PMID:25978154 DOI: 10.1097/ccm.0000000000000958]

59 Reindl-Schwaighofer R, Kainz A, Jelencsics K, Heinzel A, Berlakovich G, Remport Á, Heinze G, Langer R, Oberbauer R. Steroid pretreatment of organ donors does not impact on early rejection and long-term kidney allograft survival: Results from a multicenter randomized, controlled trial. Am J Transplant 2019; 19: 1770-1776 [PMID:30614649 DOI: 10.1111/ajt.15252]

60 Matschek S, Wilflingseder J, Pones M, Kainz A, Bodingbauer M, Mühlbacher F, Langer RM, Gerlei Z, Oberbauer R. The effect of steroid pretreatment of deceased organ donors on liver allograft function: a blinded randomized placebo-controlled trial. J Hepatol 2012; 56: 1305-1309 [PMID:22326464 DOI: 10.1016/j.jhep.2012.01.020]

61 van Erp AC, van Dullemen LFA, Ploeg RJ, Leuvenink HGD. Systematic review on the treatment of deceased organ donors. Transplant Rev (Orlando) 2018; 32: 194-206 [PMID: 30049604 DOI: 10.1016/j.trre.2018.06.001]

62 Saidi RF, Chang J, Verb S, Brooks S, Nalbantoglu I, Adsay V, Jacobs MJ. The effect of methylprednisolone on warm ischemia-reperfusion injury in the liver. Am J Surg 2007; 193: 345-347; discussion 347-348 [PMID:17320532 DOI: 10.1016/j.amjsurg.2006.09.017]

63 Van Zanden JE, A't Hart N, Ottens PJ, Liu B, Rebolledo RA, Erasmus ME, Leuvenink HGD. Methylprednisolone treatment in brain death-induced lung inflammation-a dose comparative study in rats. Front Pharmacol 2021; 12: 587003 [PMID: 33692687DOI: 10.3389/fphar.2021.587003]

64 Paulus P, Holfeld J, Urbschat A, Mutlak H, Ockelmann PA, Tacke S, Zacharowski K, Reissig C, Stay D, Scheller B. Prednisolone as preservation additive prevents from ischemia reperfusion injury in a rat model of orthotopic lung transplantation. PloS one 2013; 8: e73298 [PMID:24009745 DOI: 10.1371/journal.pone.0073298]

65 Messer SJ, Axell RG, Colah S, White PA, Ryan M, Page AA, Parizkova B, Valchanov K, White CW, Freed DH, Ashley E, Dunning J, Goddard M, Parameshwar J, Watson CJ, Krieg T, Ali A, Tsui S, Large SR. Functional assessment and transplantation of the donor heart after circulatory death. J Heart Lung Transplant 2016; 35: 1443-1452 [PMID: 27916176 DOI: 10.1016/j.healun.2016.07.004]

66 Ardehali A, Esmailian F, Deng M, Soltesz E, Hsich E, Naka Y, Mancini D, Camacho M, Zucker M, Leprince P, Padera R, Kobashigawa J. Ex-vivo perfusion of donor hearts for human heart transplantation (PROCEED II): A prospective, open-label, multicentre, randomised non-inferiority trial. Lancet 2015; 385: 2577-2584 [PMID:25888086 DOI: 10.1016/s0140-6736(15)60261-6 
67 Dharnidharka VR, Schnitzler MA, Chen J, Brennan DC, Axelrod D, Segev DL, Schechtman KB, Zheng J, Lentine KL. Differential risks for adverse outcomes 3 years after kidney transplantation based on initial immunosuppression regimen: A national study. Transplant Int 2016; 29: 1226-1236 [PMID:27564782 DOI: 10.1111/tri.12850]

68 Anesi JA, Lautenbach E, Tamma PD, Thom KA, Blumberg EA, Alby K, Bilker WB, Werzen A, Tolomeo P, Omorogbe J, Pineles L, Han JH. Risk factors for extendedspectrum $\beta$-lactamase-producing enterobacterales bloodstream infection among solid-organ transplant recipients. Clin Infect Dis 2021; 72: 953-960 [PMID:32149327 DOI: $10.1093 / \mathrm{cid} /$ ciaa190]

69 Margalit I, Goldberg E, Ben Ari Y, Ben-Zvi H, Shostak Y, Krause I, Muhsen K. Clinical correlates of nocardiosis. Sci Rep 2020; 10: 14272 [PMID:32868850 DOI: 10.1038/s41598-020-71214-4]

70 Steinbrink J, Leavens J, Kauffman CA, Miceli MH. Manifestations and outcomes of nocardia infections: Comparison of immunocompromised and nonimmunocompromised adult patients. Medicine (Baltimore) 2018; 97: e12436 [PMID:30290600 DOI: 10.1097/md.0000000000012436]

71 Nucci M, Engelhardt M, Hamed K. Mucormycosis in south america: A review of 143 reported cases. Mycoses 2019; 62: 730-738 [PMID:31192488 DOI: 10.1111/myc.12958]

72 Matthews H, Rohde H, Wichmann D, Kluge S. Invasive Pulmonary Aspergillosis. Deutsch Med Wochenschr 2019; 144: 1218-1222 [PMID:31454845 DOI: 10.1055/a0817-7432]

73 Smolovic B, Vukcevic B, Muhovic D, Ratkovic M. Renal aspergillosis in a liver transplant patient: A case report and review of literature. World J Clin Cases 2018; 6: 1155-1159 [PMID:30613674 DOI: 10.12998/wjcc.v6.i16.1155]

74 Fishman JA, Gans H. Pneumocystis jiroveci in solid organ transplantation: Guidelines from the american society of transplantation infectious diseases community of practice. Clin Transplant 2019; 33: e13587 [PMID:31077616 DOI: 10.1111/ctr.13587]

75 Permpalung N, Kittipibul V, Mekraksakit P, Rattanawong P, Nematollahi S, Zhang SX, Mehta Steinke S. A comprehensive evaluation of risk factors for pneumocystis jirovecii pneumonia in adult solid organ transplant recipients: A systematic review and meta-analysis. Transplantation 2020; [PMID:33323766 DOI: 10.1097/tp.0000000000003576]

76 Kaminski H, Belliere J, Burguet L, Del Bello A, Taton B, Poirot-Mazères S, Accoceberry I, Delhaes L, Visentin J, Gregori M, Iriart X, Charpentier E, Couzi L, Kamar N, Merville P. Identification of predictive markers and outcomes of lateonset pneumocystis jirovecii pneumonia in kidney transplant recipients. Clin Infect Dis 2020; ciaa1611 [PMID:33095856 DOI: 10.1093/cid/ciaa1611]

77 Lee HY, Choi SH, Kim T, Chang J, Kim SH, Lee SO, Kim MN, Sung H. Epidemiologic trends and clinical features of pneumocystis jirovecii pneumonia in 
non-hiv patients in a tertiary-care hospital in korea over a 15-year-period. Jpn J Infect Dis 2019; 72: 270-273 [PMID: 30918147 DOI: 10.7883/yoken.JJID.2018.400]

78 Mundo W, Morales-Shnaider L, Tewahade S, Wagner E, Archuleta S, Bandali M, Chadalawada S, Johnson SC, Franco-Paredes C, Shapiro L, Henao-Martínez AF. Lower mortality associated with adjuvant corticosteroid therapy in non-hivinfected patients with pneumocystis jirovecii pneumonia: A single-institution retrospective us cohort study. Open Forum Infect Dis 2020; 7: ofaa354 [PMID:33005696 DOI: 10.1093/ofid/ofaa354]

79 Moon SM, Kim T, Sung H, Kim MN, Kim SH, Choi SH, Jeong JY, Woo JH, Kim YS, Lee SO. Outcomes of moderate-to-severe pneumocystis pneumonia treated with adjunctive steroid in non-hiv-infected patients. Antimicrob Agents Chemother 2011; 55: 4613-4618 [PMID:21788460 DOI: 10.1128/aac.00669-11]

80 Samannodi M, Vaghefi-Hosseini R, Nigo M, Guevara EY, Hasbun R. Risk classification for respiratory viral infections in adult solid organ transplantation recipients. Transplant Proc 2021; 53: 737-742 [PMID:33272649 DOI: 10.1016/j.transproceed.2020.10.011]

81 Mahan LD, Kanade R, Mohanka MR, Bollineni S, Joerns J, Kaza V, Torres F, La Hoz RM, Banga A. Characteristics and outcomes among patients with communityacquired respiratory virus infections during the first year after lung transplantation. Clin Transplant 2021; 35: e14140 [PMID:33146445 DOI: 10.1111/ctr.14140]

82 Gu J, Su QQ, Zuo TT, Chen YB. Adenovirus diseases: a systematic review and meta-analysis of 228 case reports. Infection 2021; 49: 1-13 [PMID:32720128 DOI: 10.1007/s15010-020-01484-7]

83 Santeusanio AD, Zendel A, Fenig Y, Mahamid A, Bhansali A, De Boccardo G, Delaney V, Farouk SS, Dunn D, Rana M, Florman S, Shapiro R. Kidney transplantation using lymphocyte depleting induction and standard maintenance immunosuppression at the height of the sars-cov-2 pandemic in new york city: A single-center experience. Clin Transplant 2020; 34: e14055 [PMID: 33439508 DOI: 10.1111/ctr.14055]

84 Willicombe M, Gleeson S, Clarke C, Dor F, Prendecki M, Lightstone L, Lucisano G, McAdoo S, Thomas D. Identification of patient characteristics associated with sars-cov-2 infection and outcome in kidney transplant patients using serological screening. Transplantation 2021; 105: 151-157 [PMID:33196625 DOI: 10.1097/tp.0000000000003526]

85 Crowhurst T, Nolan J, Faull R, Holmes M, Holmes-Liew CL. Bk virus-associated nephropathy in a lung transplant patient: Case report and literature review. BMC Infect Dis 2020; 20: 600 [PMID:32795251 DOI: 10.1186/s12879-020-05292-0]

86 Sandkovsky U, Qiu F, Kalil AC, Florescu A, Wilson N, Manning C, Florescu DF. Risk factors for the development of cytomegalovirus resistance in solid organ transplantation: a retrospective case-control study. Transplant Proc 2018; 50: 37633768 [PMID:30577267 DOI: 10.1016/j.transproceed.2018.08.009] 
87 Van Damme E, Sauviller S, Lau B, Kesteleyn B, Griffiths P, Burroughs A, Emery $\mathrm{V}$, Sinclair J, Van Loock M. Glucocorticosteroids trigger reactivation of human cytomegalovirus from latently infected myeloid cells and increase the risk for hcmv infection in $\mathrm{d}+\mathrm{r}+$ liver transplant patients. J Gen Virol 2015; 96: 131-143 [PMID:25312585 DOI: 10.1099/vir.0.069872-0]

88 González-Naranjo LA, Coral-Enríquez JA, Restrepo-Escobar M, Muñoz-Vahos CH, Jaramillo-Arroyave D, Vanegas-García AL, Eraso R, Vásquez G, Jaimes F. Factors associated with active tuberculosis in colombian patients with systemic lupus erythematosus: a case-control study. Clin Rheumatol 2021; 40: 181-191 [PMID:32529420 DOI: 10.1007/s10067-020-05225-x]

89 Miglioli-Galvão L, Pestana JOM, Lopes-Santoro G, Torres Gonçalves R, Requião Moura LR, Pacheco Silva Á, Camera Pierrotti L, David Neto E, Santana Girão E, Costa de Oliveira CM, Saad Abboud C, Dias França J, Devite Bittante C, Corrêa L, Aranha Camargo LF. Severe strongyloides stercoralis infection in kidney transplant recipients: A multicenter case-control study. PLoS Negl Trop Dis 2020; 14: e0007998 [PMID:32004346 DOI: 10.1371/journal.pntd.0007998]

90 Clemente W, Vidal E, Girão E, Ramos AS, Govedic F, Merino E, Muñoz P, Sabé N, Cervera C, Cota GF, Cordero E, Mena A, Montejo M, López-Medrano F, Aguado JM, Fernandes P, Valerio M, Carratalá J, Moreno A, Oliveira J, Mourão PH, TorreCisneros J. Risk factors, clinical features and outcomes of visceral leishmaniasis in solid-organ transplant recipients: a retrospective multicenter case-control study. Clin Microbiol Infect 2015; 21: 89-95 [PMID:25636932 DOI: 10.1016/j.cmi.2014.09.002]

91 Wang C, Huo Y, Li X, Lin A, Hu Q, Xiong C, Deng Y. Factors related to bone metabolism in kidney transplant recipients. Mediators Inflamm 2021; 2021: 6679095 [PMID: 33510582 DOI: 10.1155/2021/6679095]

92 Torregrosa JV, Ferreira AC, Cucchiari D, Ferreira A. Bone mineral disease after kidney transplantation. Calcif Tissue Int 2021, 108: 551-560. [PMID:33765230 DOI: 10.1007/s00223-021-00837-0]

93 Batteux B, Gras-Champel V, Lando M, Brazier F, Mentaverri R, Desailly-Henry I, Rey A, Bennis Y, Masmoudi K, Choukroun G, Liabeuf S. Early steroid withdrawal has a positive effect on bone in kidney transplant recipients: a propensity score study with inverse probability-of-treatment weighting. Ther Adv Musculoskelet Dis 2020; 12: 1759720x20953357 [PMID:33193832 DOI: 10.1177/1759720x20953357]

94 Pérez-Sáez MJ, Herrera S, Prieto-Alhambra D, Vilaplana L, Nogués X, Vera M, Redondo-Pachón D, Mir M, Güerri R, Crespo M, Díez-Pérez A, Pascual J. Maintenance low dose systemic glucocorticoids have limited impact on bone strength and mineral density among incident renal allograft recipients: a pilot prospective cohort study. Bone 2018; 116: 290-294 [PMID:30145341 DOI: 10.1016/j.bone.2018.08.013]

95 Oya A, Umezu T, Ogawa R, Nishiwaki T, Niki Y, Nakamura M, Matsumoto M, Kanaji A. Short-term outcomes of total hip arthroplasty after liver transplantation. Arthroplast Today 2021; 8: 11-14 [PMID: 33665276 DOI: 10.1016/j.artd.2021.01.001] 
96 Takao M, Abe H, Sakai T, Hamada H, Takahara S, Sugano N. Transitional changes in the incidence of hip osteonecrosis among renal transplant recipients. J Orthop Sci 2020; 25: 466-471 [PMID:31280930 DOI: 10.1016/j.jos.2019.06.009]

97 Felten R, Perrin P, Caillard S, Moulin B, Javier RM. Avascular osteonecrosis in kidney transplant recipients: risk factors in a recent cohort study and evaluation of the role of secondary hyperparathyroidism. PloS one 2019; 14: e0212931 [PMID: 30794689 DOI: 10.1371/journal.pone.0212931]

98 Yang J, Jing M, Yang X. Association between genetic polymorphisms and osteonecrosis in steroid treatment populations: a detailed stratified and doseresponse meta-analysis. Biosci Rep 2019; 39: [PMID:30966113 DOI: 10.1042/bsr20190024]

99 Tronche F, Opherk C, Morigg1 R, Kellendonk C, Reimann A, Schwake L, Reichardt HM, Stangl K, Gau D, Hoeflich A, Beug H, Schmid W, Schutz G. Glucocorticoid receptor function in hepatocytes is essential to promote postnatal body growth. Genes Dev 2004; 18: 492-497 [PMID: 15037546 DOI: 10.1101/gad.284704]

100 Delucchi Á, Toro L, Alzamora R, Barrientos V, González M, Andaur R, León P, Villanueva F, Galindo M, Las Heras F, Montecino M, Moena D, Lazcano A, Pinto V, Salas P, Reyes ML, Mericq V, Michea L. Glucocorticoids decrease longitudinal bone growth in pediatric kidney transplant recipients by stimulating the fgf23/fgfr3 signaling pathway. J Bone Miner Res 2019; 34: 1851-1861 [PMID: 31099911 DOI: $10.1002 /$ jbmr.3761]

101 McCaffrey J, Shenoy M. Acute rejection and growth outcomes in paediatric kidney allograft recipients treated with a corticosteroid minimisation immunosuppressive protocol. Pediatr Nephrol 2021, 10.1007/s00467-021-04948-6: [PMID:33560455 DOI: 10.1007/s00467-021-04948-6]

102 Kusumi K, Shaikhkhalil A, Patel HP, Mahan JD. Promoting bone health in children and adolescents following solid organ transplantation. Pediatr Transplant 2021; 25: e13940 [PMID:33341105 DOI: 10.1111/petr.13940]

103 Dalle H, Garcia M, Antoine B, Boehm V, Do TTH, Buyse M, Ledent T, Lamaziere A, Magnan C, Postic C, Denis RG, Luquet S, Feve B, Moldes M. Adipocyte glucocorticoid receptor deficiency promotes adipose tissue expandability and improves the metabolic profile under corticosterone exposure. Diabetes 2019; 68: 305-317 [PMID:30455377 DOI: 10.2337/db17-1577]

104 Cruz-Topete D, Oakley RH, Carroll NG, He B, Myers PH, Xu X, Watts MN, Trosclair K, Glasscock E, Dominic P, Cidlowski JA. Deletion of the cardiomyocyte glucocorticoid receptor leads to sexually dimorphic changes in cardiac gene expression and progression to heart failure. J Am Heart Assoc 2019; 8: e011012 [PMID:31311395 DOI: 10.1161/JAHA.118.011012]

105 Shivaswamy V, Boerner B, Larsen J. Post-transplant diabetes mellitus: Causes, treatment, and impact on outcomes. Endocr Rev 2016; 37: 37-61 [PMID:26650437 DOI: $10.1210 /$ er.2015-1084] 
106 Kgosidialwa O, Blake K, O'Connell O, Egan J, O'Neill J, Hatunic M. Posttransplant diabetes mellitus associated with heart and lung transplant. Ir J Med Sci 2020; 189: 185-189 [PMID:31352656 DOI: 10.1007/s11845-019-02068-7]

107 Guad RM, Taylor-Robinson AW, Wu YS, Gan SH, Zaharan NL, Basu RC, Liew CSL, Wan Md Adnan WAH. Clinical and genetic risk factors for new-onset diabetes mellitus after transplantation (NODAT) in major transplant centres in malaysia. BMC Nephrol 2020; 21: 388 [PMID:32894076 DOI: 10.1186/s12882-02002052-9]

108 Tillmann FP, Schmitz M, Rump LC, Quack I. Impact of low-dose steroids on hba1c levels and development of pre-diabetes and nodat in non-diabetic renal transplant recipients on long-term follow-up. Int Urol Nephrol 2018; 50: 771-777 [PMID: 29197933 DOI: 10.1007/s11255-017-1754-0]

109 Toshima T, Yoshizumi T, Inokuchi S, Kosai-Fujimoto Y, Kurihara T, Yoshiya S, Mano Y, Takeishi K, Itoh S, Harada N, Ikegami T, Soejima Y, Shimokawa M, Maehara Y, Mori M. Risk factors for the metabolic syndrome components of hypertension, diabetes mellitus, and dyslipidemia after living donor liver transplantation. HPB (Oxford) 2020; 22: 511-520 [PMID:31561946 DOI: 10.1016/j.hpb.2019.08.008]

110 Kathirvel M, Mallick S, Sethi P, Thillai M, Durairaj MS, Nair K, Sunny A, Mathew JS, Varghese CT, Chandran B, Pillai Thankamony Amma BS, Menon RN, Balakrishnan D, Gopalakrishnan U, Surendran S. Randomized trial of steroid free immunosuppression with basiliximab induction in adult live donor liver transplantation (ldlt). HPB (Oxford) 2020; S1365-182x(20)31157-6 [PMID:33032883 DOI: 10.1016/j.hpb.2020.09.012]

111 ADA's standards of medical care in diabetes. Clinical diabetes 2021Suppl 1; 39: 128 [PMID:33298409 PMC7839602 DOI: 10.2337/cd21-pe01]

112 Choi HK, Seeger JD. Glucocorticoid use and serum lipid levels in us adults: The third national health and nutrition examination survey. Arthritis Rheum 2005; 53: 528-535 [PMID:16082633 DOI: 10.1002/art.21329]

113 Höcker B, Weber LT, John U, Drube J, Fehrenbach H, Klaus G, Pohl M, Seeman T, Fichtner A, Wühl E, Tönshoff B. Steroid withdrawal improves blood pressure control and nocturnal dipping in pediatric renal transplant recipients: Analysis of a prospective, randomized, controlled trial. Pediatr Nephrol 2019; 34: 341-348 [PMID:30178240 DOI: 10.1007/s00467-018-4069-1]

114 Ahmad N, Khan TFT, Nadeem N, Fourtounas K. Steroid-sparing and steroidbased immunosuppression in kidney transplant: Is there a difference in outcomes and recipient comorbidities? Exp Clin Transplant 2020; 18: 572-576 [PMID:32635885 DOI: 10.6002/ect.2020.0067]

115 Goodwin JE, Zhang J, Gonzalez D, Albinsson S, Geller DS. Knockout of the vascular endothelial glucocorticoid receptor abrogates dexamethasone-induced hypertension. J Hypertens 2011; 29: 1347-1356 [PMID:21659825 DOI: 10.1097/HJH.0b013e328347da54] 
116 Goodwin JE, Feng Y, Velazquez H, Zhou H, Sessa WC. Loss of the endothelial glucocorticoid receptor prevents the therapeutic protection afforded by dexamethasone after lps. PloS one 2014; 9: e108126 [PMID:25299055 DOI: 10.1371/journal.pone.0108126]

117 Goodwin JE, Feng Y, Velazquez H, Sessa WC. Endothelial glucocorticoid receptor is required for protection against sepsis. Proc Natl Acad Sci U S A 2013; 110: 306311 [PMID: 23248291 DOI: 10.1073/pnas.1210200110]

118 Faravelli I, Velardo D, Podestà MA, Ponticelli C. Immunosuppression-related neurological disorders in kidney transplantation. J Nephrol 2021, 10.1007/s40620020-00956-1: [PMID:33481222 DOI: 10.1007/s40620-020-00956-1]

119 Watson ML, Baehr LM, Reichardt HM, Tuckermann JP, Bodine SC, Furlow JD. A cell-autonomous role for the glucocorticoid receptor in skeletal muscle atrophy induced by systemic glucocorticoid exposure. Am J Physiol Endocrinol Metab 2012; 302: E1210-1220 [PMID:22354783 DOI: 10.1152/ajpendo.00512.2011]

120 Valentin A, Borresen SW, Rix M, Elung-Jensen T, Sørensen SS, Feldt-Rasmussen U. Adrenal insufficiency in kidney transplant patients during low-dose prednisolone therapy: a cross-sectional case-control study. Nephrol Dial Transplant 2020; 35: 2191-2197 [PMID: 31539081 DOI: 10.1093/ndt/gfz180]

121 Vulto A, Minović I, de Vries LV, Timmermans AC, van Faassen M, Gomes Neto AW, Touw DJ, de Jong MFC, van Beek AP, Dullaart RPF, Navis G, Kema IP, Bakker SJL. Endogenous urinary glucocorticoid metabolites and mortality in prednisolone-treated renal transplant recipients. Clin Transplant 2020; 34: e13824 [PMID:32052523 DOI: 10.1111/ctr.13824]

122 de Vries LV, de Jong WHA, Touw DJ, Berger SP, Navis G, Kema IP, Bakker SJL. Twenty-four hour urinary cortisol excretion and the metabolic syndrome in prednisolone-treated renal transplant recipients. Steroids 2017; 127: 31-39 [PMID:28893559 DOI: 10.1016/j.steroids.2017.09.001]

123 Tielemans MM, van Boekel GAJ, van Gelder T, Tjwa ET, Hilbrands LB. Immunosuppressive drugs and the gastrointestinal tract in renal transplant patients. Transplant Rev (Orlando) 2019; 33: 55-63 [PMID:30473173 DOI: 10.1016/j.trre.2018.11.001]

124 Gibson CM, Childs-Kean LM, Naziruddin Z, Howell CK. The alteration of the gut microbiome by immunosuppressive agents used in solid organ transplantation. Transplant Infect Dis 2021; 23: e13397 [PMID: 32609940 DOI: 10.1111/tid.13397]

125 Garmpis N, Spartalis E, Schizas D, Patsouras D, Damaskos C, Spartalis M, Garmpi A, Nikiteas NI, Dimitroulis D. Incisional hernias post liver transplantation: Current evidence of epidemiology, risk factors and laparoscopic versus open repair. A review of the literature. In Vivo 2019; 33: 1059-1066 [PMID:31280193 DOI: 10.21873/invivo.11574]

126 Fagenson AM, Mazzei M, Edwards MA. Does steroid use in transplant patients undergoing bariatric surgery independently impact outcomes? J Surg Res 2020; 254: 294-299 [PMID: 32502779 DOI: 10.1016/j.jss.2020.04.024] 
127 Tuyls S, Verleden SE, Wuyts WA, Yserbyt J, Vos R, Verleden GM. Determinants of survival in lung transplantation patients with idiopathic pulmonary fibrosis: A retrospective cohort study. Transpl Int 2019; 32: 399-409 [PMID: 30488486 DOI: 10.1111/tri.13382]

128 Kim HE, Paik HC, Kim SY, Park MS, Lee JG. Preoperative corticosteroid use and early postoperative bronchial anastomotic complications after lung transplantation. Korean J Thorac Cardiovasc Surg 2018; 51: 384-389 [PMID:30588446 DOI: $10.5090 /$ kjtcs.2018.51.6.384]

129 Guengerich FP. Cytochrome p-450 3a4: Regulation and role in drug metabolism. Annu Rev Pharmacol Toxicol 1999; 39: 1-17 [PMID:10331074 DOI: 10.1146/annurev.pharmtox.39.1.1]

130 Lebrun-Vignes B, Archer VC, Diquet B, Levron JC, Chosidow O, Puech AJ, Warot D. Effect of itraconazole on the pharmacokinetics of prednisolone and methylprednisolone and cortisol secretion in healthy subjects. Br J Clin Pharmacol 2001; 51: 443-450 [PMID:11422002 DOI: 10.1046/j.1365-2125.2001.01372.x]

131 Fost DA, Leung DY, Martin RJ, Brown EE, Szefler SJ, Spahn JD. Inhibition of methylprednisolone elimination in the presence of clarithromycin therapy. $J$ Allergy Clin Immunol 1999; 103: 1031-1035 [PMID:10359882 DOI: 10.1016/s00916749(99)70175-2]

132 Shihab FS, Lee ST, Smith LD, Woodle ES, Pirsch JD, Gaber AO, Henning AK, Reisfield R, Fitzsimmons W, Holman J. Effect of corticosteroid withdrawal on tacrolimus and mycophenolate mofetil exposure in a randomized multicenter study. Am J Transplant 2013; 13: 474-484 [PMID:23167508 DOI: 10.1111/j.16006143.2012.04327.x]

133 Hosohata K, Uesugi M, Hashi S, Hosokawa M, Inui K, Matsubara K, Ogawa K, Fujimoto Y, Kaido T, Uemoto S, Masuda S. Association between CYP3A5 genotypes in graft liver and increase in tacrolimus biotransformation from steroid treatment in living-donor liver transplant patients. Drug Metab Pharmacokinet 2014; 29: 83-89 [PMID: 23955548 DOI: 10.2133/dmpk.dmpk-13-rg-060]

134 Al-Kofahi M, Oetting WS, Schladt DP, Remmel RP, Guan W, Wu B, Dorr CR, Mannon RB, Matas AJ, Israni AK, Jacobson PA. Precision dosing for tacrolimus using genotypes and clinical factors in kidney transplant recipients of european ancestry. J Clin Pharmacol 2021; [PMID:33512723 DOI: 10.1002/jcph.1823]

135 Ost L. Impairment of prednisolone metabolism by cyclosporine treatment in renal graft recipients. Transplantation 1987; 44: 533-535 [PMID: 3313841]

136 Bergmann TK, Isbel NM, Barraclough KA, Campbell SB, McWhinney BC, Staatz CE. Comparison of the influence of cyclosporine and tacrolimus on the pharmacokinetics of prednisolone in adult male kidney transplant recipients. Clin Drug Investig 2014; 34: 183-188 [PMID: 24385281 DOI: 10.1007/s40261-013-0162-1]

137 Skauby RH, Gustavsen MT, Andersen AM, Bjerre A, Åsberg A, Midtvedt K, Vethe NT, Bergan S. Prednisolone and prednisone pharmacokinetics in adult renal transplant recipients. Ther Drug Monit 2021; 43: 247-255 [PMID: 33181621 DOI: $10.1097 / \mathrm{ftd} .0000000000000835]$ 
138 Richardson RV, Batchen EJ, Denvir MA, Gray GA, Chapman KE. Cardiac gr and mr: From development to pathology. Trends Endocrinol Metab 2016; 27: 35-43 [PMID: 26586027 DOI: 10.1016/j.tem.2015.10.001]

139 Ferguson D, Hutson I, Tycksen E, Pietka TA, Bauerle K, Harris CA. Role of mineralocorticoid receptor in adipogenesis and obesity in male mice. Endocrinology 2020; 161: [PMID:32036385 DOI: 10.1210/endocr/bqz010]

140 Bauersachs J, Jaisser F, Toto R. Mineralocorticoid receptor activation and mineralocorticoid receptor antagonist treatment in cardiac and renal diseases. Hypertension 2015; 65: 257-263 [PMID:25368026 DOI: 10.1161/HYPERTENSIONAHA.114.04488

141 John K, Marino JS, Sanchez ER, Hinds Jr TD. The glucocorticoid receptor: Cause of or cure for obesity? Am J Physiol Endocrinol Metab 2016; 310: E249-257 [PMID: 26714851 DOI: 10.1152/ajpendo.00478.2015]

142 Jacob KA, Leaf DE, Dieleman JM, van Dijk D, Nierich AP, Rosseel PM, van der Maaten JM, Hofland J, Diephuis JC, de Lange F, Boer C, Kluin J, Waikar SS, Dexamethasone for Cardiac Surgery Study G. Intraoperative high-dose dexamethasone and severe AKI after cardiac surgery. J Am Soc Nephrol 2015; 26: 2947-2951 [PMID: 25952257 DOI: 10.1681/ASN.2014080840]

143 Nader N, Ng SS, Lambrou GI, Pervanidou P, Wang Y, Chrousos GP, Kino T. Ampk regulates metabolic actions of glucocorticoids by phosphorylating the glucocorticoid receptor through p38 mapk. Mol Endocrinol 2010; 24: 1748-1764 [PMID:20660302 DOI: 10.1210/me.2010-0192]

144 Liu J, Pang L, Ng KTP, Chiu TLS, Liu H, Liu X, Xu A, Lo CM, Man K. Compromised ampk-pgclalpha axis exacerbated steatotic graft injury by dysregulating mitochondrial homeostasis in living donor liver transplantation. Ann Surg 2020; [PMID:32889872 DOI: 10.1097/SLA.0000000000004468] 